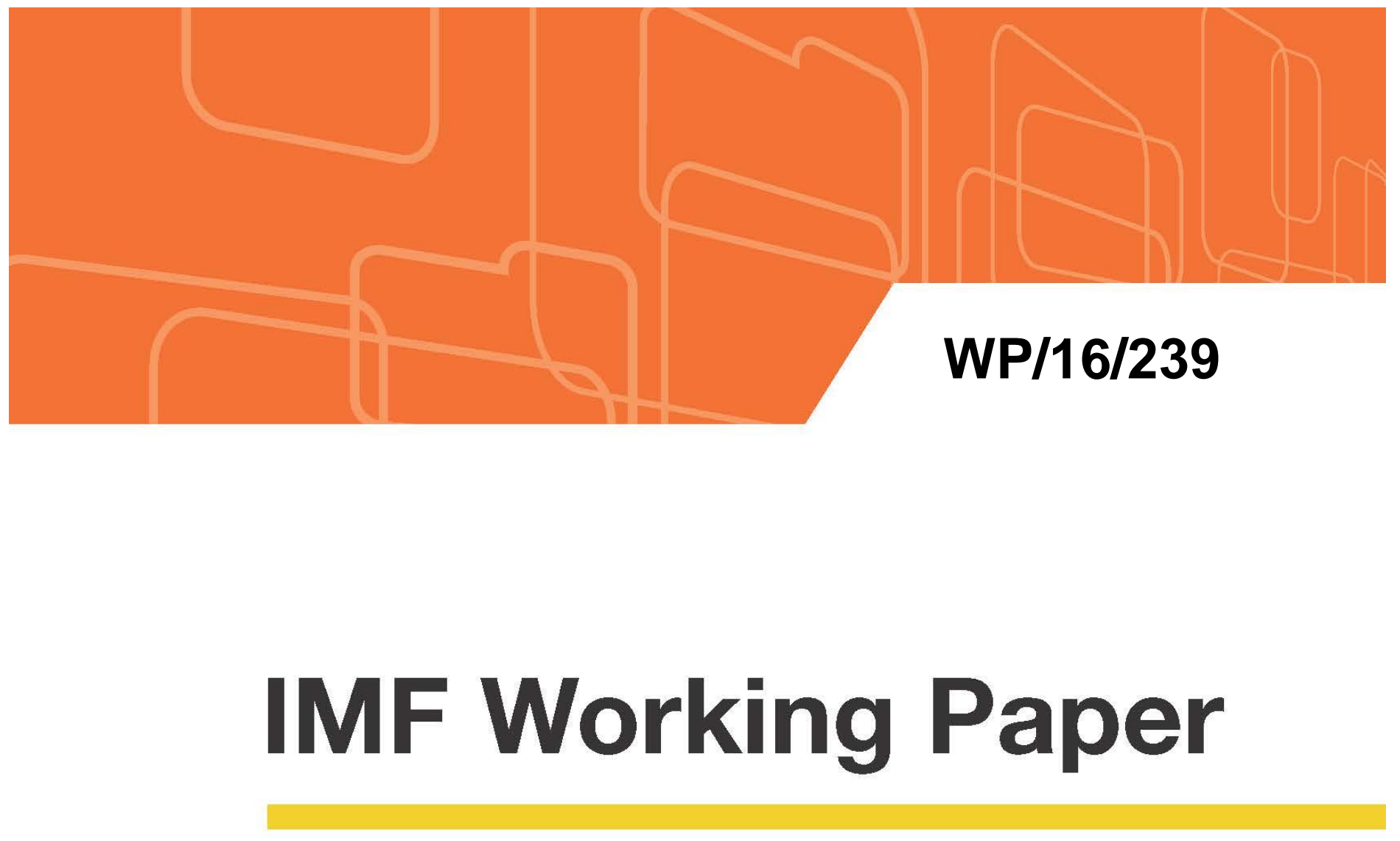

\title{
A Tale of Transition: An Empirical Analysis of Economic Inequality in Urban China, 1986-2009
}

by Haiyan Ding and Hui He

IMF Working Papers describe research in progress by the author(s) and are published to elicit comments and to encourage debate. The views expressed in IMF Working Papers are those of the author(s) and do not necessarily represent the views of the IMF, its Executive Board, or IMF management. 


\title{
IMF Working Paper
}

Institute for Capacity Development

\begin{abstract}
A Tale of Transition: An Empirical Analysis of Economic Inequality in Urban China, 1986-2009'
\end{abstract}

\section{Prepared by Haiyan Ding and Hui He}

Authorized for distribution by Laura Kodres

August 2016

\section{IMF Working Papers describe research in progress by the author(s) and are published to elicit comments and to encourage debate. The views expressed in IMF Working Papers are those of the author(s) and do not necessarily represent the views of the IMF, its Executive Board, or IMF management.}

\begin{abstract}
This paper is the first comprehensive empirical study of earnings, income, and consumption inequality in urban China from 1986 to 2009, using unique micro-level data from the Urban Household Survey (UHS). The paper documents a drastic increase in economic inequality for the sample period. The paper finds that consumption inequality closely tracks income inequality, both over time and over the life cycle. The paper believes that the main driver of this co-movement could be a dramatic increase in noninsurable idiosyncratic permanent income shocks after the early 1990s, associated with the economic transition in urban China.

\footnotetext{
${ }^{1}$ Ding: China Institute for Income Distribution, Beijing Normal University and School of Economics, Shanghai University of Finance and Economics; He: International Monetary Fund and Shanghai University of Finance and Economics. We thank Jinhui Bai, Yan Bai, Fatih Guvenen, Jonathan Heathcote, Mark Huggett, Laura Kodres, Dirk Krueger, Geng Li, Lei Ning, Victor Rios-Rull, Evan Tanner, Chao Wei, Xiaobo Zhang, Shenghao Zhu, Xiaodong Zhu, and participants from various seminars and conferences for helpful comments and suggestions. We are especially grateful to Dirk Krueger, who encouraged us to initiate this project. Hui He thanks research support sponsored by Shanghai Pujiang Program (No. 2013140026) and the Program for Professor of Special Appointment (Eastern Scholar) at Shanghai Institutions of Higher Learning (No. 2013140034).
} 
JEL Classification Numbers: D31; D91; E21

Keywords: Inequality over time and life-cycle; Income dynamics; Chinese economy; Structural transformation

Author's E-Mail Address: yan201308@gmail.com; hhe@imf.org; 


\section{Contents}

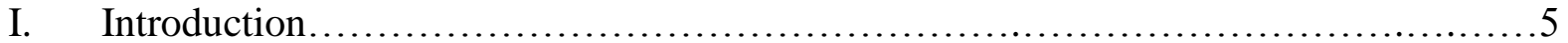

II. Background of China's Economic Transformation................................. 8

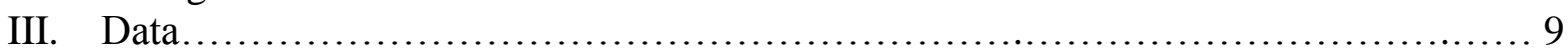

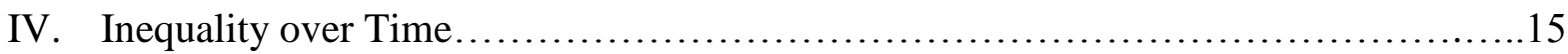

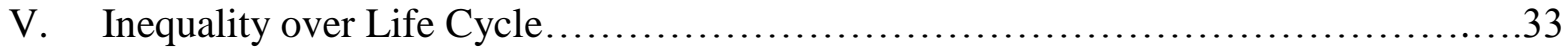

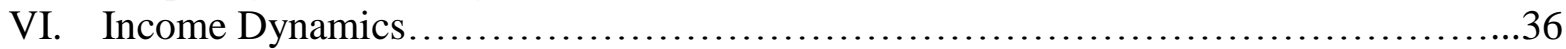

VII. Conclusion............................................................45

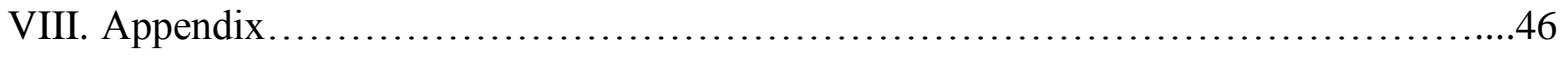

\section{List of Tables}

Table 1. Sample Size of UHS ..................................................11

Table 2. Summary Statistics of Demographic Characteristics in UHS .....................13

Table 3. Panel Construction from UHS: Three-year Panel for Difference Method...........48

Table 4. Panel Construction from UHS: Two-year Panel for Level Method..................49

Table 5. Sample Mean of Constructed Three-Year Panel and Original UHS: Comparison...49

\section{List of Figures}

Figure 1. Comparison between UHS and Macro Data.............................. 14

Figure 2. Various Measures of Household Earnings Inequality.............................16

Figure 3. Percentiles of the Household Earnings Distribution............................. 17

Figure 4. Various Measures of Equivalized Household Earnings Inequality.................18

Figure 5. The Role of Government in Income Inequality ............................... 19

Figure 6. From Pre-government to Disposable Income................................20

Figure 7. From Disposable Income to Consumption.................................21

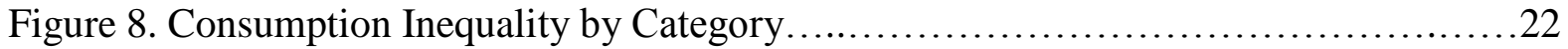

Figure 9. From Disposable Income to Nondurable Consumption..........................23

Figure 10. From Disposable Income to Nondurable Consumption: Equivalent Household

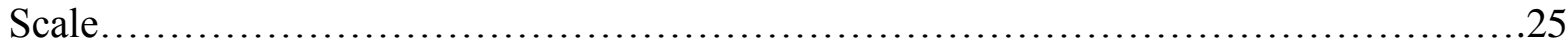

Figure 11. Income and Consumption Inequality: Public versus Private Sector..............26

Figure 12. Income and Consumption Inequality by Region...........................27

Figure 13. Income and Consumption Inequality: Hukou versus Migrated Workers..........28

Figure 14. Income and Consumption Inequality: Nine Provinces for 1986-2009............29

Figure 15. Between-group versus Within-group Inequality............................. 31

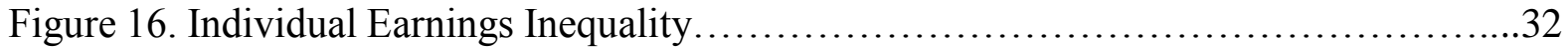

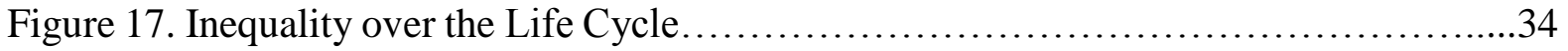

Figure 18. Inequality over the Life Cycle: Equivalent Household Scale.......................35

Figure 19. Household Saving Rate by Income Quintiles.................................. 37

Figure 20. Transitory versus Permanent Income Shocks................................39

Figure 21. Income Shock: SOEs versus POEs......................................42

Figure 22. Income Shock by Education...........................................43

Figure 23. Income Shock by Age ............................................44

Figure 24. Transitory versus Permanent Income Shocks: Relaxed Age Restriction...........50 


\section{INTRODUCTION}

Over the past three decades, the world witnessed a fast-growing and changing Chinese economy. With tremendous economic growth, there is an increasing concern among policymakers and the public on widening economic inequality in China. Compared to our knowledge on China's growth miracle, we know much less about the trend of economic inequality. This paper aims to fill the gap by providing the first comprehensive view of rising economic inequality in China for the period 1986-2009.

Employing unique micro-level annual urban household survey (UHS) data from 1986 to 2009, this paper empirically investigates the evolution of inequality in earnings, income, and consumption in urban China for this time period. To make the analysis consistent with the literature and also comparable with other country studies, we closely follow the methodology in the Review of Economic Dynamics (RED) 2010 special issue on "Cross-Sectional Facts for Macroeconomists" in our sample selection and data processing.

We find that economic inequality has been increasing drastically in China, as the public has been speculating. For example, the variance of log household disposable income in China increased from 0.14 in 1986 to 0.43 in 2009, almost threefold over 24 years. The speed of increase is far higher than in any country covered in the RED special issue. ${ }^{1}$ We also find that total consumption inequality is higher than disposable income inequality for most of the period. Nondurable consumption inequality, however, is slightly lower than disposable income inequality. This implies that durable consumption inequality is much higher than disposable income inequality.

What surprised us most is that consumption inequality, whether total consumption or nondurable consumption, closely tracks disposable income inequality over time. This pattern contrasts sharply to what we found in the United States and other advanced economies. In those countries, consumption inequality has been increasing much more slowly than income inequality. Also, the level of consumption inequality is usually significantly lower than that of income inequality. This pattern is viewed as strong evidence of consumption smoothing (Krueger and Perri 2006). Russia is the only country studied in the RED special issue that shows consumption inequality is higher than income inequality during the time period that it was investigated

\footnotetext{
${ }^{1}$ Variance of log of labor income had increased more than 20 percent in the United States for the time period 1980-2003 (see Krueger and Perri 2006) and that of disposable income had increased slightly more than 40 percent in Japan for the time period 1981-2005 (see Lise et al. 2014).
} 
(Gorodnichenko, Peter and Stolyarov 2010). However, even in the Russian case, consumption inequality does not track as closely with income inequality as it does in China.

We also look at the evolution of inequality over the life cycle, following the method employed in Deaton and Paxson (1994). We find that the variances of log household earnings, disposable income, and nondurable consumption all rise over the life cycle, consistent with the pattern observed in the U.S. data (see Heathcote, Perri, and Violante 2010). However, the variance of log disposable income closely tracks that of nondurable consumption over the entire life cycle, which is consistent with the timeseries pattern mentioned previously in this section. At the same time, we observe in the U.S. data a divergence between disposable income and nondurable consumption inequality over the life cycle.

This unique fact of strong co-movement between income and consumption inequality over both time and the life cycle probably indicates limited risk-sharing across individuals over time. We investigate two possible explanations for the co-movement. First, it could be the sign of the prevailing existence of "hand-to-mouth" consumers (or more precisely, the "rule-of-thumb" consumers described in Campell and Mankiw 1989). ${ }^{2}$ "Hand-to-mouth" consumers are individuals who simply consume what they earn. With consumption roughly equal to income, their variance is also roughly equal. This theory implies that the saving rate should be close to zero among households. However, in the data, only the lowest income quintile of households have their average saving rate close to zero. For other income quintiles, we observe significantly positive saving rates. More important, the household saving rate rises over time for all other income quintiles. We thus conclude that except in the lowest income quintile, little evidence supports the existence of "hand-to-mouth" consumers in urban China.

Our second explanation lies in the changes of underlying income shock structure. The literature shows that it is much more difficult for households to insure against idiosyncratic permanent income shocks than against idiosyncratic transitory income shocks (Blundell, Pistaferri and Preston 2008). Therefore a possible explanation of why consumption inequality closely tracks income inequality in urban China is that rising permanent income shocks dominates the transitory income shocks over time. It

\footnotetext{
${ }^{2}$ See Kaplan, Violante, and Weinder (2014) for a nice survey on the "hand-to-mouth" (HtM) consumers. They document that HtM consumers (both wealthy and poor HtM) have a significantly higher marginal propensity to consume in response to transitory income shocks than non hand-tomouth consumers.
} 
makes the uninsurable part of idiosyncratic income shock increase over time, and thus impedes the efficient risk-sharing among households that can smooth consumption. To test this hypothesis, we estimate labor income dynamics following the literature (Heathcote, Perri, and Violante 2010). We explore the panel structure of the urban household survey to construct a two- or three-period short panel at the household level. As in Heathcote, Perri, and Violante (2010), we use a method with moments based on income growth rates ("difference") and a method with moments based on log income levels ("level"). As found in Heathcote, Perri, and Violante (2010) and other articles in the RED special issue, we find that there is a substantial divergence between the average transitory and permanent variances obtained by two methods. Like Heathcote, Perri, and Violante (2010), we find that the "level" method is subject to a severe mis-specification problem. On the other hand, the "difference" method gives us reasonable estimation. In addition, the "difference" method of estimating the income process is commonly used in labor economics (e.g., Blundell, Pistaferri and Preston 2008). We therefore think that the "difference" method gives a more accurate estimation of income process in China.

The estimation by the "difference" method shows that the permanent income shock has been increasing significantly relative to the transitory income shock since the mid-1990s. From 1994 to 2005, permanent income variance in urban China increased from 0.01 to 0.095 ; that is, by about eight times. In contrast, transitory income variance decreased from 0.04 to 0.017 for the same time period. Taking into account that individuals can only partially insure against a permanent income shock and almost fully insure against a transitory income shock (Blundell, Pistaferri and Preston 2008), the underlying change in the composition of income shocks implies that it is getting more difficult to share risk across individuals over time, which leads to a synchronization between consumption and income inequality. We believe that this could be a plausible story behind the observed co-movement of income and consumption inequality.

We make a further effort to investigate what causes the substantial increase in idiosyncratic permanent income shocks in urban China since the mid-1990s. As shown in more detail in the next section, tremendous economic transformation pushing the economy to be more market-oriented took place since the mid 1990s. A large number of state-owned enterprises (SOEs) have been either privatized or simply shut down. During the economic transition, evidence shows that less educated, relatively older workers face higher chances of being laid off (Appleton and others 2002). Motivated by these facts, we further decompose the income process estimation along three di- 
mensions: enterprise ownership, worker age, and education. Our results show that workers who work for privately-owned enterprises (POEs), who are relatively older and who have less education tend to have higher permanent income variance. This finding provides the evidence that economic transformation might be a important driving force behind that fundamental change of the underlying income shock structure. In that sense, we think the co-movement of income and consumption inequality in China could be a tale of transition. The transition in urban China created tremendous uncertainty and led to an increase in uninsurable income shock, which passes on to rising consumption inequality.

The paper is organized as follows. We provide a brief historical background on the Chinese economy over the past three decades in Section 2. Section 3 describes our dataset and sample selection criteria. Section 4 shows the trend of economic inequality over time. Section 5 investigates the economic inequality over the life cycle. Section 6 estimates income dynamics using the panel structure in the UHS dataset and further investigates the possible cause of the substantial increase in permanent income shock. Section 7 concludes.

\section{BACKGROUND OF CHINA'S ECONOMIC TRANSFORMATION}

In this section, we provide a brief historical background on the Chinese economy over the past three decades, with particular focus on the economic reforms that took place in urban China.

In 1978, Chinese leader Deng Xiaoping initiated the "Open Door" policy and economic reform after the end of the devastating Cultural Revolution. After the successful household responsibility reform in rural areas, the focus of economic reform shifted to cities in 1984. State control of industry was relaxed. POEs were allowed to operate and compete with SOEs. And POEs gradually expanded their market share at the expense of SOEs. However, corruption and rising inflation led to political turmoil in 1989, which halted the market-oriented reform and triggered an economic crisis.

In 1992, during his famous tour to south China, Deng Xiaoping pushed for further radical reform toward a market economy in urban areas. Privatization began to accelerate afterwards. The private sector surpassed the state sector in terms of the share of GDP for the first time in the mid-1990s. The economic troubles ensuing 
from the inefficiency of money-losing SOEs finally prompted the Chinese government to initiate a large-scale privatization of SOEs in 1997 under the slogan "Grasp the Big, Let Go of the Small" (see Hsieh and Song 2015 for details). Except large SOEs in strategic sectors (energy, electricity, telecommunications, and banking), a majority of small to medium-sized SOEs were either privatized or allowed to go bankrupt. Accompanying the SOE reform, a series of reforms on privatizing social security, education, health care, and housing were carried out. During the period of largescale restructuring reform from 1997 to 2002, more than 35 million SOE workers were laid off (He and others 2015). The landscape of the Chinese urban economy was changed forever.

After the SOE reform, growth accelerated. China's accession to the World Trade Organization (WTO) in 2001 further boosted growth. The annual real GDP growth rate exceeded 10 percent on average from 2002 to 2011. The private sector accounted for more than 60 percent of GDP in 2012. China's economy has been transformed into a market-oriented dynamic economy.

\section{DATA}

In this section, we describe the two micro-level household survey datasets used. Our main dataset is the annual Urban Household Survey (UHS). We also use the Chinese Household Income Project (CHIP) to measure wealth inequality.

\section{A Urban Household Survey (UHS)}

The UHS is conducted by the National Bureau of Statistics (NBS) of China. The UHS is based on a multi-stage probabilistic sample and stratified design, similar to that used in the Current Population Surveys (CPS) in the U.S. The UHS provides detailed information about income, consumption expenditure and the demographic characteristics of household members at the household and individual levels. In that sense, it can be viewed as the Chinese counterpart of a combination of CPS and Consumer Expenditure Survey (CEX) in the United States And it has begun to gain attention in the research community. ${ }^{3}$

\footnotetext{
${ }^{3}$ Researchers have used UHS to study the Chinese saving rate (Song and Yang 2010, Chamon and Prasad 2010), wage structure (Ge and Yang 2014), and income and consumption inequalities
} 
The NBS draws a first-stage sample (called "big sample") of households randomly from selected cities and towns in each province every three years. A final sample (called "small sample") is then randomly selected from the big sample for recurrent interviews and diary-keeping for detailed consumption expenditure every month. From 1986 to 2005, every year one third of the households in the final sample is replaced by other households from the first-stage sample. Since 2007, each year half of the households in the small sample are replaced. ${ }^{4}$ The design means that it should be possible to construct a short panel (two- or three-year period) on the household and individual levels from this rotation structure. The survey questionnaires have been updated several times since 1986. Two major changes were made in 1992 and 2002 and minor changes were made in 1997 and 2007.

The UHS is not publicly available. The portion of the UHS data to which we had access covers the time period from 1986 to 2009. The number of provinces and households covered varies across years. For time period 1986-1992, we have, on average, more than 12,000 households per year from 28 provinces covering the whole country. For 1993-1997, we have data for just under 6,000 households from 10 provinces (Beijing, Shanxi, Liaoning, Jiangsu, Anhui, Hubei, Guangdong, Chongqing, Sichuan, Gansu) per year. For 1998-2001, we have access to the data covering nine provinces (Beijing, Liaoning, Zhejiang, Anhui, Hubei, Guangdong, Sichuan, Shanxi, Gansu) with 5,450 households per year. For time period 2002-2009, UHS reports household and individual data separately. ${ }^{5}$ We have access to the data for more than 30,000 households and more than 120,000 individuals per year (except 2002, for which we have 26,990 households and 109,326 individuals) and they cover 16 provinces (Beijing, Shanxi, Liaoning, Heilongjiang, Shanghai, Jiangsu, Anhui, Jiangxi, Shandong, Henan, Hubei, Guangdong, Chongqing, Sichuan, Yunnan, Gansu).

Table 1 summarizes the sample size of our access to the UHS for different years.

(Cai, Chen, and Zou 2010), among others.

${ }^{4}$ As pointed out by Feng, Hu and Moffitt (2015), this rotation design has not always been strictly enforced. Probably because of budget constraints, the rotation ratio is always lower than what was originally designed as we document in Section 6 and Appendix B (especially in Tables 3 and 4).

${ }^{5}$ Before 2002, the UHS does not separate household and individual variables in two sets of tables. However, each household member does have an ID that we can use to track individuals across years. See Appendix B on how we use it to construct a short panel from the UHS. 
Table 1: Sample Size of UHS

\begin{tabular}{|l|l|l|}
\hline Year & \# of Observations & \# of Provinces \\
\hline 1986 & 11660 & 28 \\
1987 & 12365 & 28 \\
1988 & 12901 & 28 \\
1989 & 12374 & 28 \\
1990 & 12827 & 28 \\
1991 & 12890 & 28 \\
1992 & 15835 & 28 \\
1993 & 5751 & 10 \\
1994 & 5899 & 10 \\
$1995-97$ & 5907 & 10 \\
$1998-01$ & 5450 & 9 \\
2002 & $26990 \mathrm{~h}, 109326 \mathrm{p}$ & 16 \\
2003 & $30384 \mathrm{~h}, 120845 \mathrm{p}$ & 16 \\
2004 & $31832 \mathrm{~h}, 127157 \mathrm{p}$ & 16 \\
2005 & $33360 \mathrm{~h}, 132453 \mathrm{p}$ & 16 \\
2006 & $33441 \mathrm{~h}, 131690 \mathrm{p}$ & 16 \\
2007 & $34462 \mathrm{~h}, 131616 \mathrm{p}$ & 16 \\
2008 & $38944 \mathrm{~h}, 154400 \mathrm{p}$ & 16 \\
2009 & $37480 \mathrm{~h}, 146205 \mathrm{p}$ & 16 \\
\hline
\end{tabular}

Source: UHS 1986-2009.

Note: "h" refers to household, "p" refers to person. 


\section{B Chinese Household Income Project Survey (CHIP)}

Our second dataset is Chinese Household Income Project (CHIP) surveys. The surveys are conducted by the Chinese Academy of Social Science (CASS) and National Bureau of Statistics (NBS) through a series of questionnaire-based interviews done in rural and urban areas in China in four different years: 1988, 1995, 2002, and $2007 .{ }^{6}$ The households in each survey are randomly selected following a strict sampling process so that they are nationally representative. The surveys cover a sample of about 15,000 to 20,000 households in 10 provinces in China. The surveys contain detailed data on household economic status, employment, levels of education, sources of income, household composition, household expenditures, and wealth. The CHIP data have been frequently used in the empirical literature. ${ }^{7}$

\section{Sample Selection}

Following the methodology in Heathcote, Perri, and Violante (2010), we construct three different data samples from the UHS and label them A, B, and C.

In sample A, we drop records from the dataset only if there is no information on the age of the head of household. We will use this sample to compare micro level data from the UHS to macro aggregates and check the consistency with macro data.

Sample B is more restricted than Sample A. First, we keep records only if the household head is aged from 25 to 60 . Then, we exclude records with negative values in household earnings, disposable income, and consumption in each year. Sample B is the main sample used for our household-level estimation.

Sample C is our individual-level sample. To construct it, we first select all individuals aged 25-60 from Sample B. We then further restrict the sample by only including individuals who report non-negative earnings.

We deflate every nominal variable by the consumer price index (base year $=2000$ ).

We summarize major household characteristics statistics based on Sample A in Table 2. Several important demographic trends are observed here. First, household size

\footnotetext{
${ }^{6}$ So far only 2007 CHIP is not publicly available.

${ }^{7}$ See Wei and Zhang (2011) and He and others (2015).
} 
Table 2: Summary Statistics of Demographic Characteristics in UHS

\begin{tabular}{|l|l|l|l|l|l|l|}
\hline & $\mathbf{1 9 8 6}$ & $\mathbf{1 9 9 0}$ & $\mathbf{1 9 9 5}$ & $\mathbf{2 0 0 0}$ & $\mathbf{2 0 0 5}$ & $\mathbf{2 0 0 9}$ \\
\hline Household size & 3.84 & 3.48 & 3.19 & 3.08 & 2.93 & 2.85 \\
Male HH head (\%) & 61.4 & 67.6 & 66.6 & 68.1 & 70.7 & 70.0 \\
\# of children & n.a. & 1.37 & 1.05 & 0.95 & 0.86 & 0.74 \\
Age of HH head & 42.3 & 44.6 & 45.6 & 47.7 & 48.9 & 49.4 \\
SOE workers (\%) & 72.0 & 70.3 & 66.3 & 56.3 & 43.7 & 35.7 \\
Above HSG (\%) & 10.1 & 15.1 & 21.8 & 26.1 & 30.1 & 32.3 \\
\# of obs & 11660 & 12827 & 5907 & 5450 & 33359 & 37462 \\
\hline
\end{tabular}

Source: UHS 1986-2009.

Note: HH is household. HSG is high school graduate.

has substantially declined over time. The average household size decreased from 3.84 in 1986 to 2.85 in 2009. The strict implementation of the "one child policy" since the early 1980s may have contributed to that dramatic decline. Second, The share of households headed by males in total households increased from 61.4 percent in 1986 to 70 percent in 2009 , possibly because of declining female labor force participation. Third, as a direct evidence of the "one child policy," the average number of children in one household declined from 1.37 in 1990 to 0.74 in 2009. Fourth, the average age of household head increased quite significantly, from 42.3 in 1986 to 49.4 in 2009, reflecting the trend of rapid aging in urban China. Fifth, reflecting the economic transition described in Section 2, the percentage of household heads working for SOEs decreased almost 100 percent, from 72.0 percent in 1986 to 35.7 percent in 2009. Finally, educational attainment has been improved significantly over the past three decades. The share of household heads who had above high school diploma more than tripled, from 10.1 percent in 1986 to 32.3 percent in $2009 .{ }^{8}$

\section{Consistency with Macro Data}

Before we begin to use the UHS to analyze inequalities in urban China, we would like to check whether the micro data from the UHS are consistent with the macro data from the China Statistical Yearbook provided by NBS.

Figure 1 reports this consistency check. Panel A shows the log of real disposable

\footnotetext{
${ }^{8}$ For comparison, the share of college graduates and above increased from 7.7 percent in 1995 to 13.6 percent in 2009 .
} 
Figure 1: Comparison between UHS and Macro Data
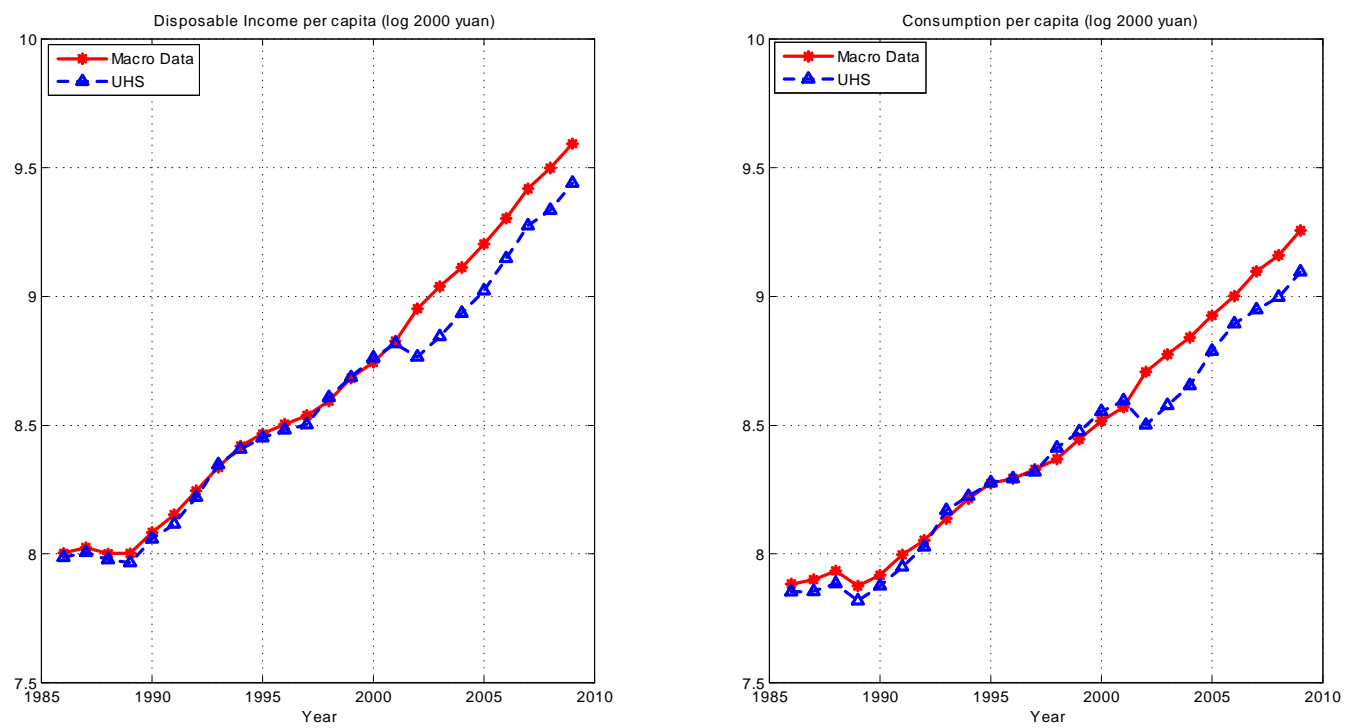

income per capita in both UHS and NBS macro data. Before 2001, the two data series were nearly identical. However, starting in 2002, possibly owing to the redesign of the UHS in that year, log real disposable income per capita decreased in the UHS and has differed from the NBS data since then. Despite this discrepancy, the trend of real disposable income in the UHS after 2002 still closely aligned with that of macro data.

Panel B in Figure 1 compares log of real consumption per capita in the UHS and NBS macro data. It shows a pattern similar to that of disposable income. The two data series aligned remarkably well before 2001 . They diverged in 2002 but kept the same trend afterwards.

The comparison verifies that the UHS is a reliable dataset, broadly consistent with the official macro data reported by NBS. We thus have the confidence to proceed with our empirical analysis based on the UHS. 


\section{INEQUALITY OVER TIME}

In this section, we report the evolution of earnings, income, consumption, and wealth inequality in urban China over the past three decades based on the UHS and CHIP data. Following the literature, we adopt four measures of inequality of the interested variables throughout the paper: the Gini coefficient, the variance of log, the ratio of the 90th percentile divided by the 50th percentile (P90/50 ratio), and the ratio of the 50 th percentile divided by the 10 th percentile (P50/10 ratio), respectively.

\section{A Household-level Inequality}

\section{A.1 Earnings}

We start with household-level inequality based on sample B. ${ }^{9}$ Figure 2 reports the four measures of dispersion of household earnings. All four measures show a dramatically increasing pattern. For example, variance of log earnings had roughly tripled, from about 0.2 in 1986 to about 0.6 in 2009. Notice that variance of log household earnings in top left panel closely resembles the P50/P10 ratio in bottom left panel. The similarity reflects the sensitivity of the variance of log to the shape of the bottom portion of the earnings distribution. In contrast, the Gini coefficient in top right panel looks similar to the P90/P50 ratio in bottom right panel. This confirms that Gini coefficient is sensitive to the upper portion of earnings distribution.

Figure 2 shows all four inequality measures of household earnings had increased significantly from 1986 to 2009. But is this because the poor are becoming poorer and the rich are becoming richer over time? Figure 3 plots the log level of household earnings by different percentiles over time (all normalized to zero in 1986). Consistent with the message in Figure 2, Figure 3 shows that the gap between different percentiles of household earnings had been widening over time. However, even for the bottom 5 and 10th percentiles, household earnings had increased about 100 log points (or in absolute level, increased about 2.72 times) from 1986 to 2009. This sharp increase in household earnings, even for the bottom income percentiles, reflects the fast growth of China's economy. Therefore the answer to the question is

\footnotetext{
${ }^{9}$ All the household-level measures are adjusted for household size by simply dividing each variable by household size.
} 
Figure 2: Various Measures of Household Earnings Inequality
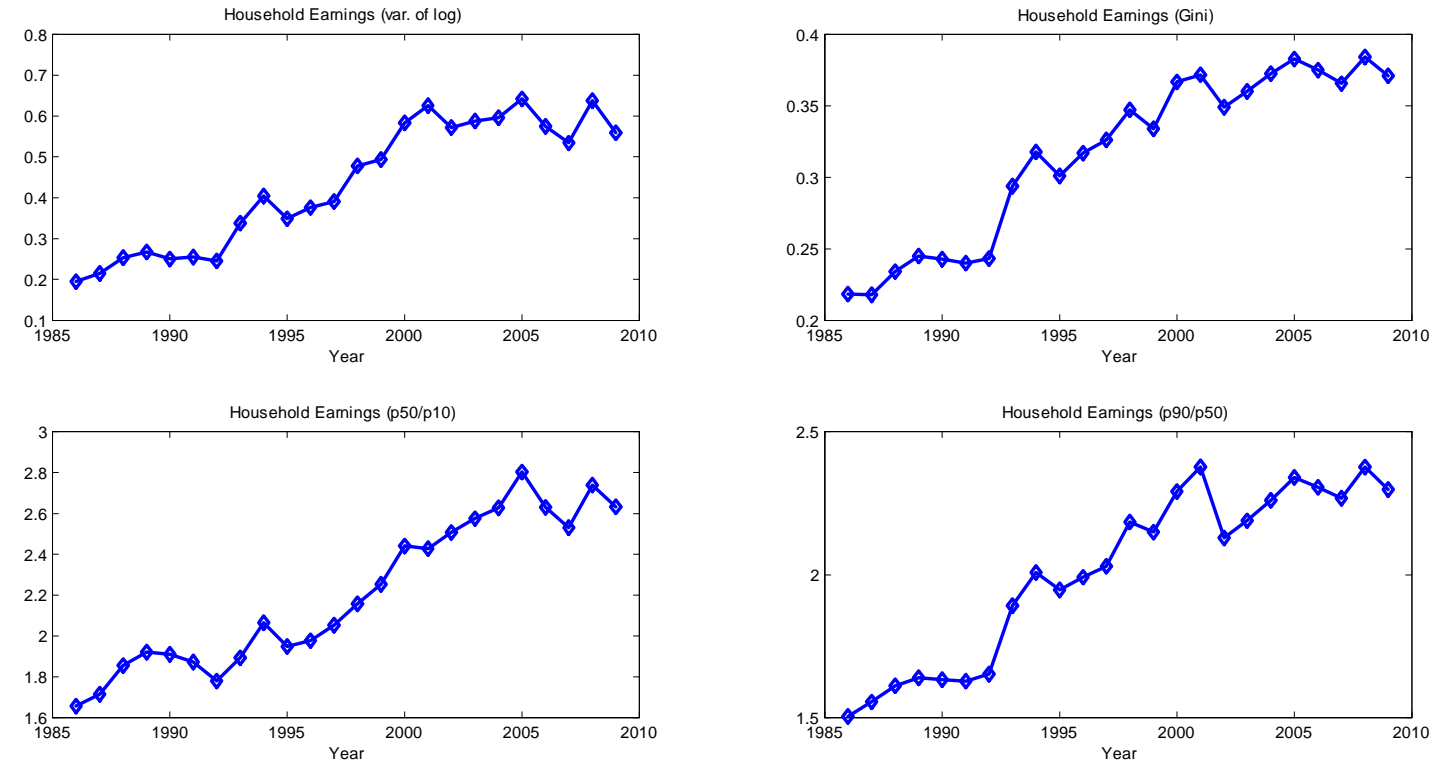
Figure 3: Percentiles of the Household Earnings Distribution

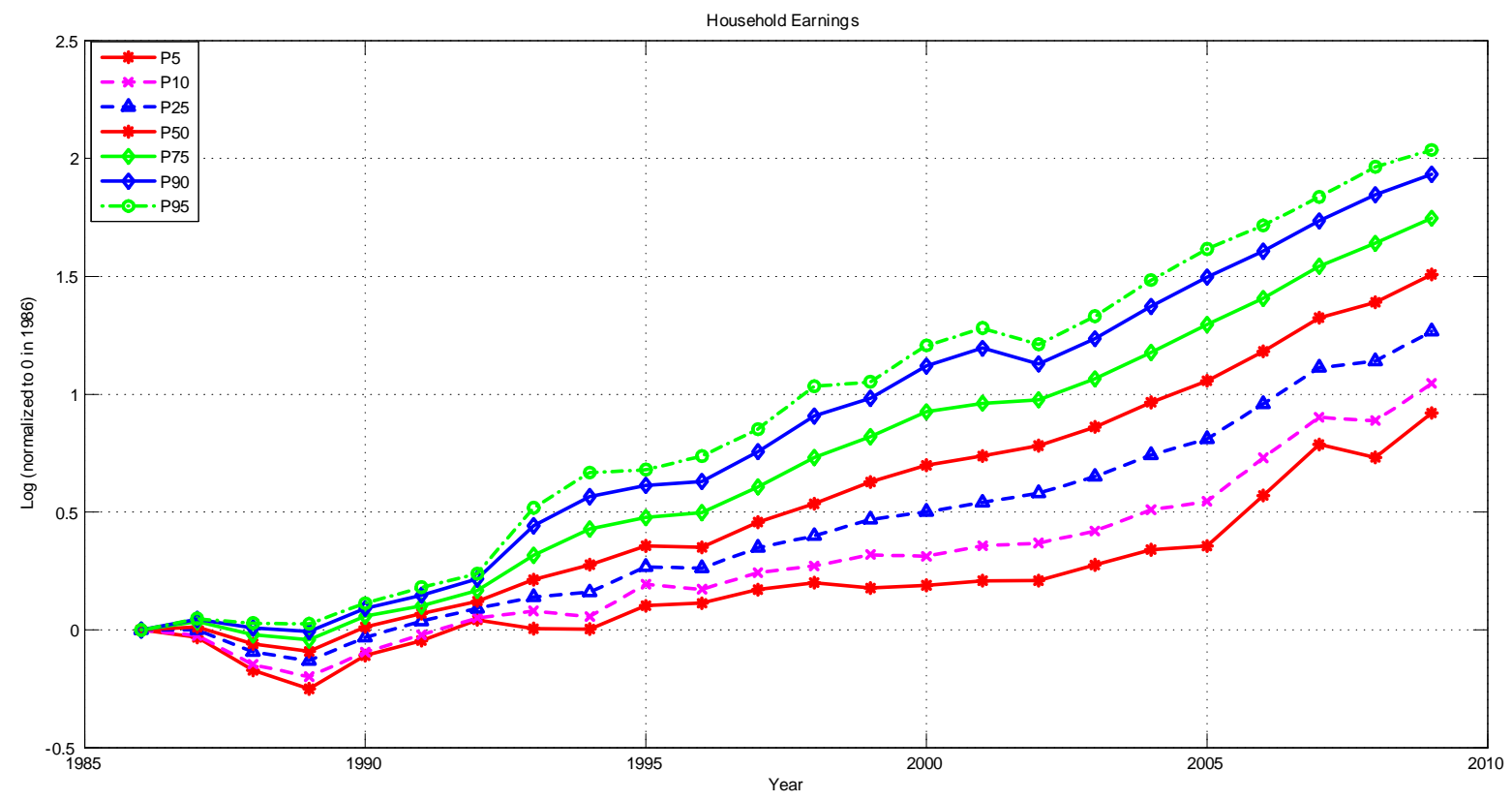

that all percentiles of earnings distribution have seen a dramatic increase over time. However, the rich have gained much more from the economic growth than the poor.

To control the possible effect of changing household composition over time, we also adjust household earnings to a per-adult-equivalent basis using the OECD equivalence scale, namely a weight of 1.0 to the first adult, 0.7 to each additional adult, and 0.5 to each child. Figure 4 shows the four dispersion measures of equivalized household earnings. As one can see, it is similar to Figure $2 .{ }^{10}$

\footnotetext{
${ }^{10}$ The UHS doesn't have information about each household member's age before 1992. Therefore we can only report equivalized earnings results from 1992.
} 
Figure 4: Various Measures of Equivalized Household Earnings Inequality
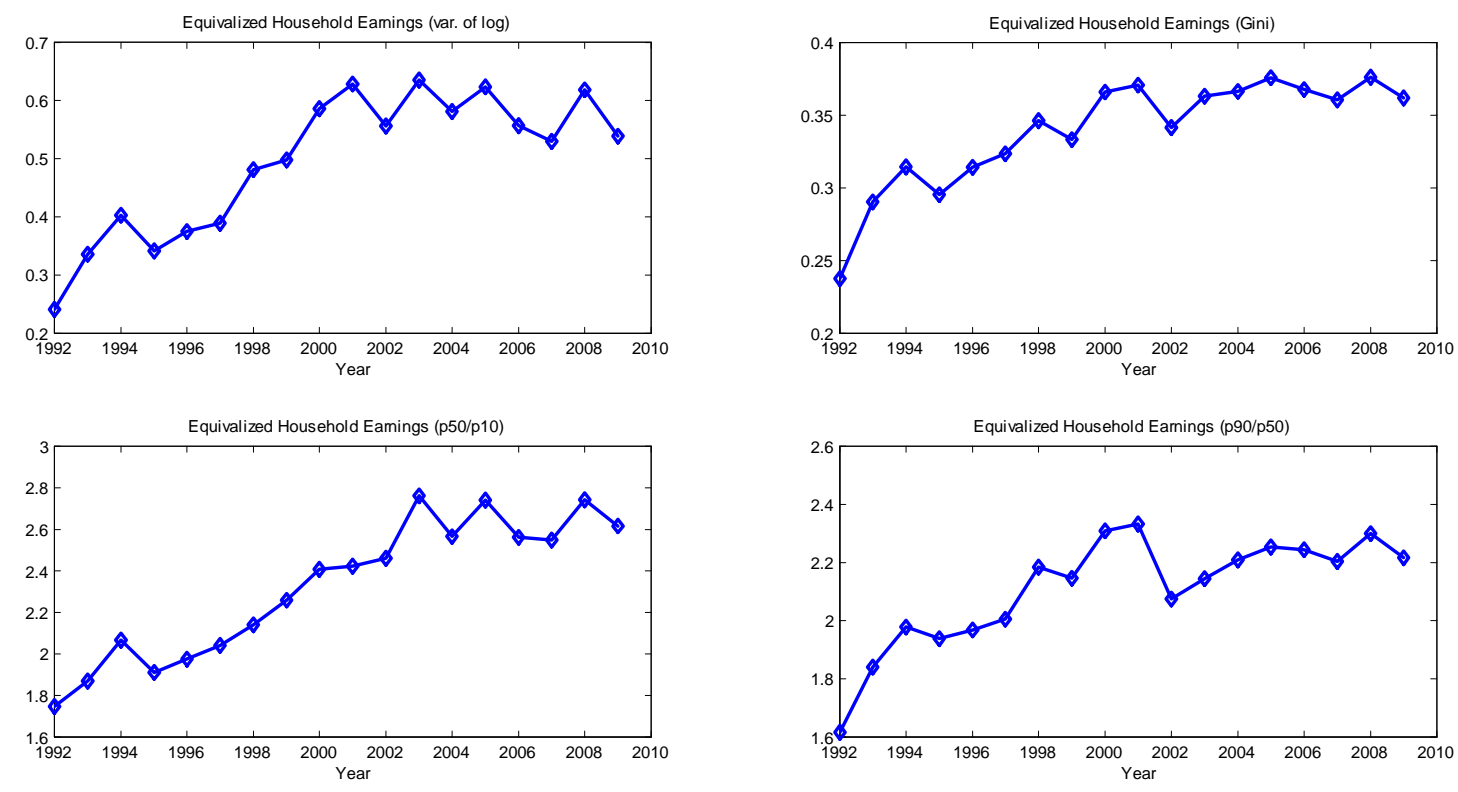
Figure 5: The Role of Government in Income Inequality
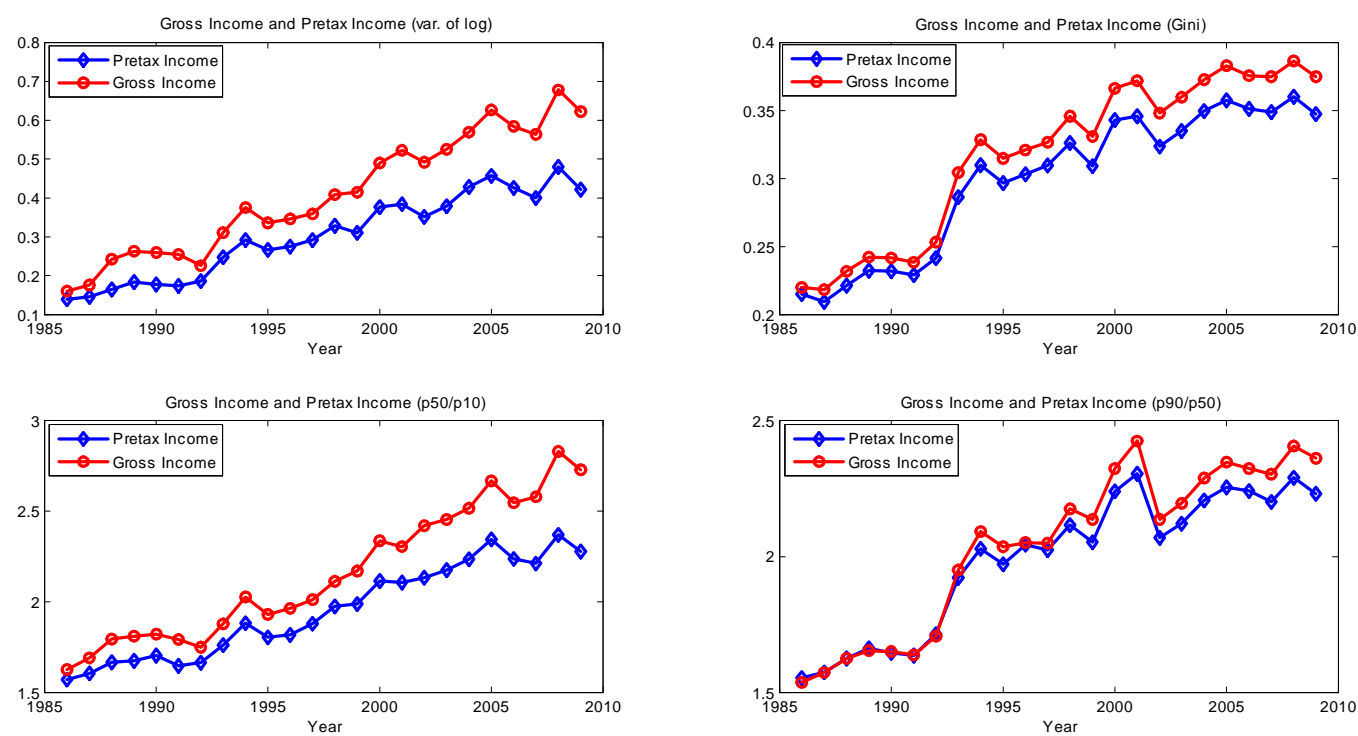

\section{A.2 Income and Government Redistribution}

What did the Chinese government do to reduce rising income inequality? Figures 5 and 6 answers the question. Figure 5 shows the evolution of both gross income and pretax income inequality at the household level. The difference between gross income and pre-tax income is public pension benefits and other social security benefits (see Appendix A). Government transfers in the form of pension benefits do significantly reduce income equality through all years for the time period 1986-2009. This is partly owing to the strong redistributional channel effected by the social security system in China. He, Ning, and Zhu (2015) document that the 1997 pension reform links the urban pension benefit to the average wage in the province where a worker retires, not her own life-cycle average wage, which implies a very strong risk-sharing and redistribution channel among retirees and also intergenerationally. The bigger discrepancy between gross income and pretax income during the later years of 19862009 for all inequality measures confirms their finding.

Figure 6 shows the evolution of pretax income and disposable income. Disposable 
Figure 6: From Pre-government to Disposable Income
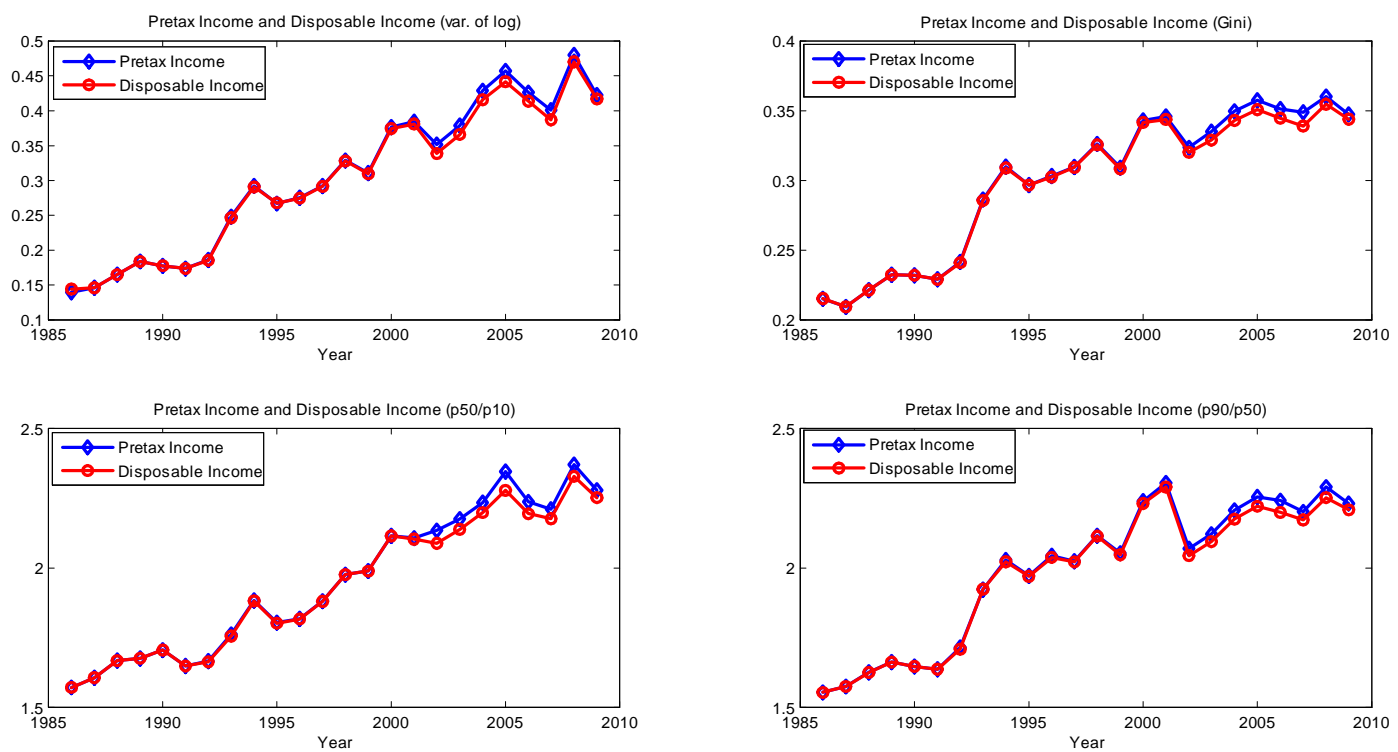

income by definition is pretax income minus taxes (see Appendix A). Here we see a much smaller difference between inequalities of pretax and disposable income than between gross income and pretax income in Figure 5. In fact, the difference was almost negligible before 2000. This pattern differs from the one in countries such as Japan. Japan shows a much bigger reduction in inequality by taxes than by transfers (see Figure 4.8 in Lise and others 2014). The reason is that unlike the case in advanced economies, labor income tax only accounts for a small fraction of Chinese government revenue and is not quite progressive. In China, income tax plays a much less important role in income redistribution than public pensions.

\section{A.3 From Disposable Income to Consumption}

For most of the countries documented in the RED special issue, a common feature is that we observe income inequality has been increasing much faster than consumption inequality. And consumption inequality is usually significantly lower than income inequality (except in Russia). This pattern reflects the improvement in risk-sharing 
Figure 7: From Disposable Income to Consumption
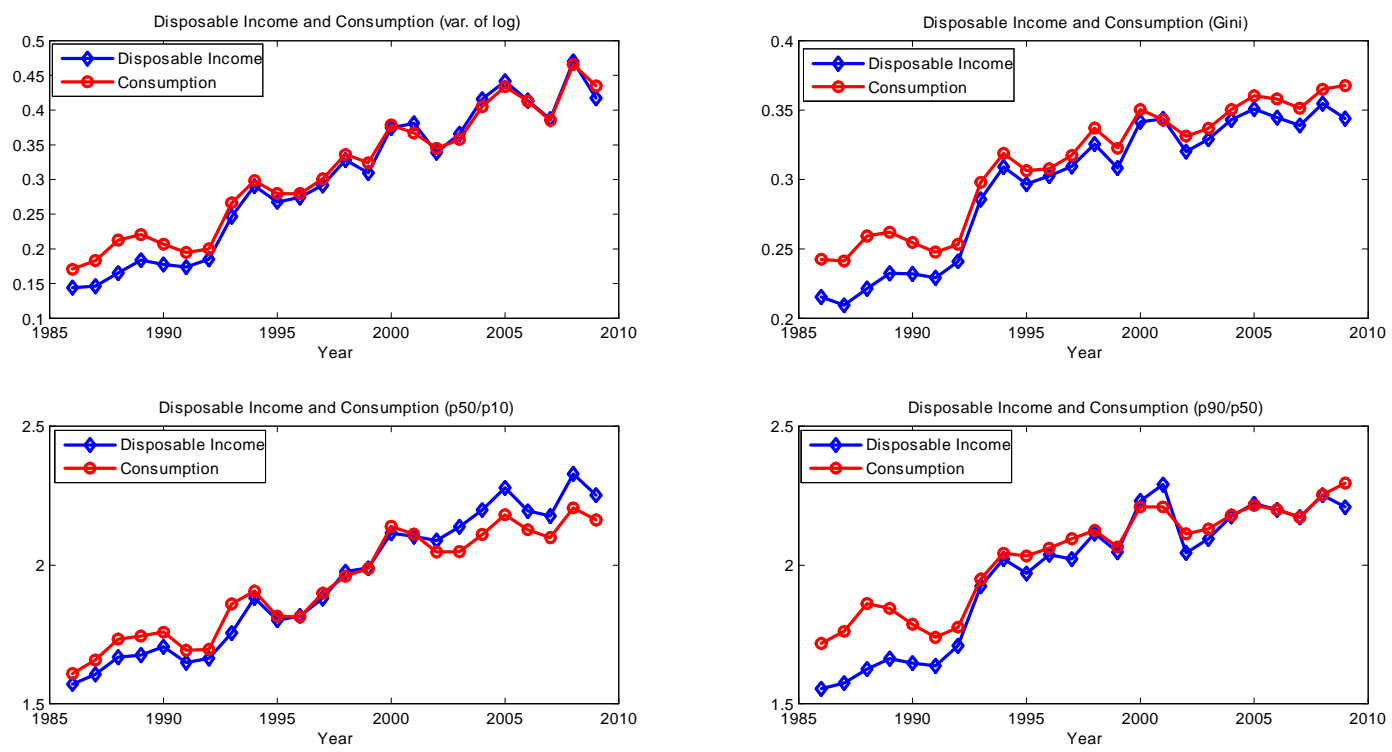

due to financial development. Consumers thus can smooth consumption relatively easy, which leads to the divergence of income and consumption inequality.

Figure 7 shows the evolution of household-level disposable income and total consumption inequality for the time period 1986-2009. China, however, shows a surprising pattern that contrasts with most countries. The Gini index of total consumption is uniformly higher than that of disposable income through the whole time period. And they closely track each other (especially after 1993). Other measures show a somewhat consistent story, although the difference between income and consumption inequality levels became less significant under the Gini measure. In all four measures, however, consumption inequality closely tracks with income inequality. ${ }^{11}$

Because the UHS has great coverage of consumption variables, we explore the consumption data by dividing it into durable versus nondurable consumption and plot their inequality respectively in Figure 8. We see that the Gini index of durable con-

\footnotetext{
${ }^{11}$ Cai, Chen, and Zhou (2010) use the UHS and document a similar pattern of income and consumption inequality for 1992-2003.
} 
Figure 8: Consumption Inequality by Category
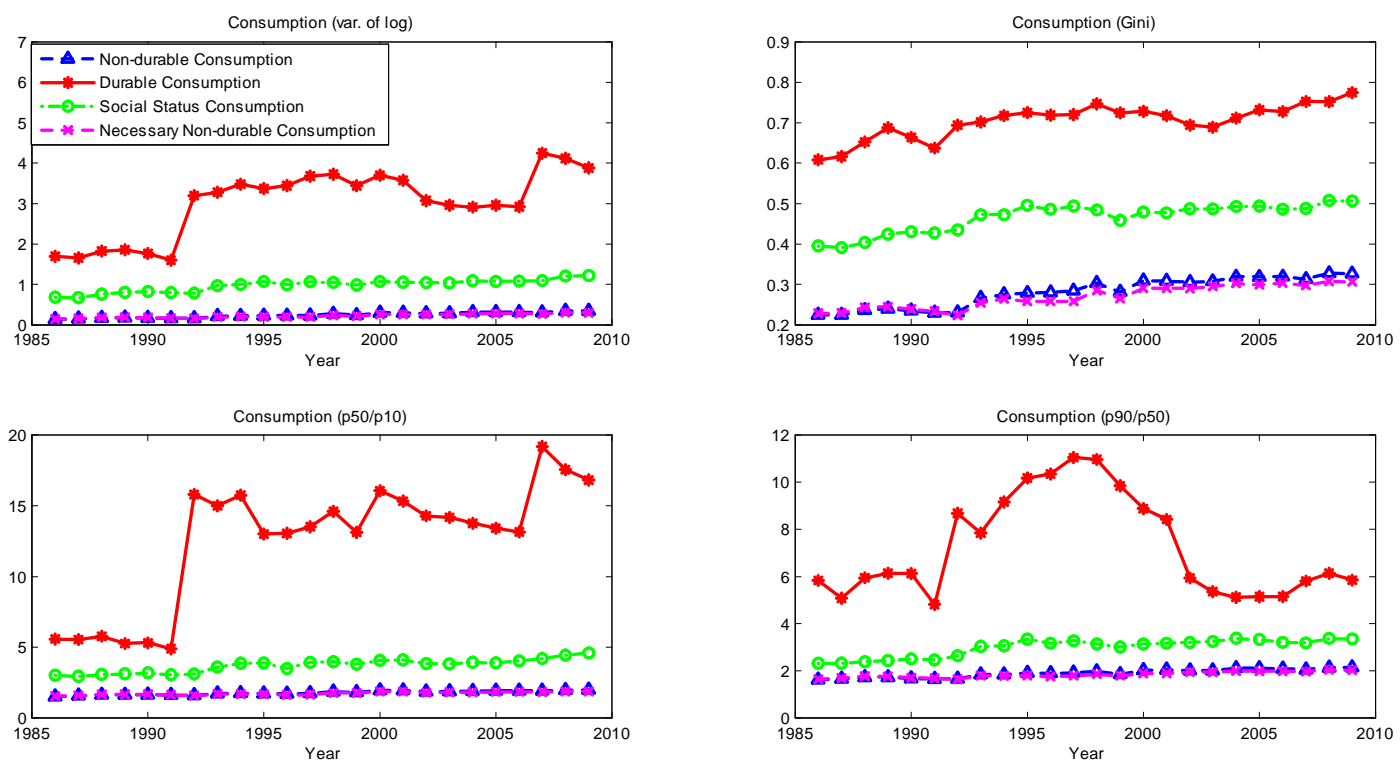

sumption is about 2-3 times higher than that of nondurable consumption. We then further differentiate nondurable consumption into necessary nondurable consumption and social status nondurable consumption. ${ }^{12}$ We find that the Gini coefficient of social status consumption is much higher than nondurable consumption, which in turn is slightly higher than necessary nondurable consumption. ${ }^{13}$

Motivated by the finding in Figure 8, we then revisit Figure 7 by replacing total consumption there with nondurable consumption. Figure 9 shows the results.

We see that nondurable consumption inequality is very close to income inequality from 1986 to 1992. This might reflect that under the centrally planned economy, workers had a very generous social safety net (so called the "iron rice bowl"). In exchange, workers received a low wage and used almost all of their income on consump-

\footnotetext{
${ }^{12}$ Social status nondurable consumption includes food away from home, education, entertainment, and personal gift. Necessary nondurable consumption = nondurable consumption - social status nondurable consumption.

${ }^{13}$ We suspect that the significant jump in 1992 and 2002 for variance of log and P50/P10 ratio is due to the change of questionnaire of UHS in those years.
} 
Figure 9: From Disposable Income to Nondurable Consumption
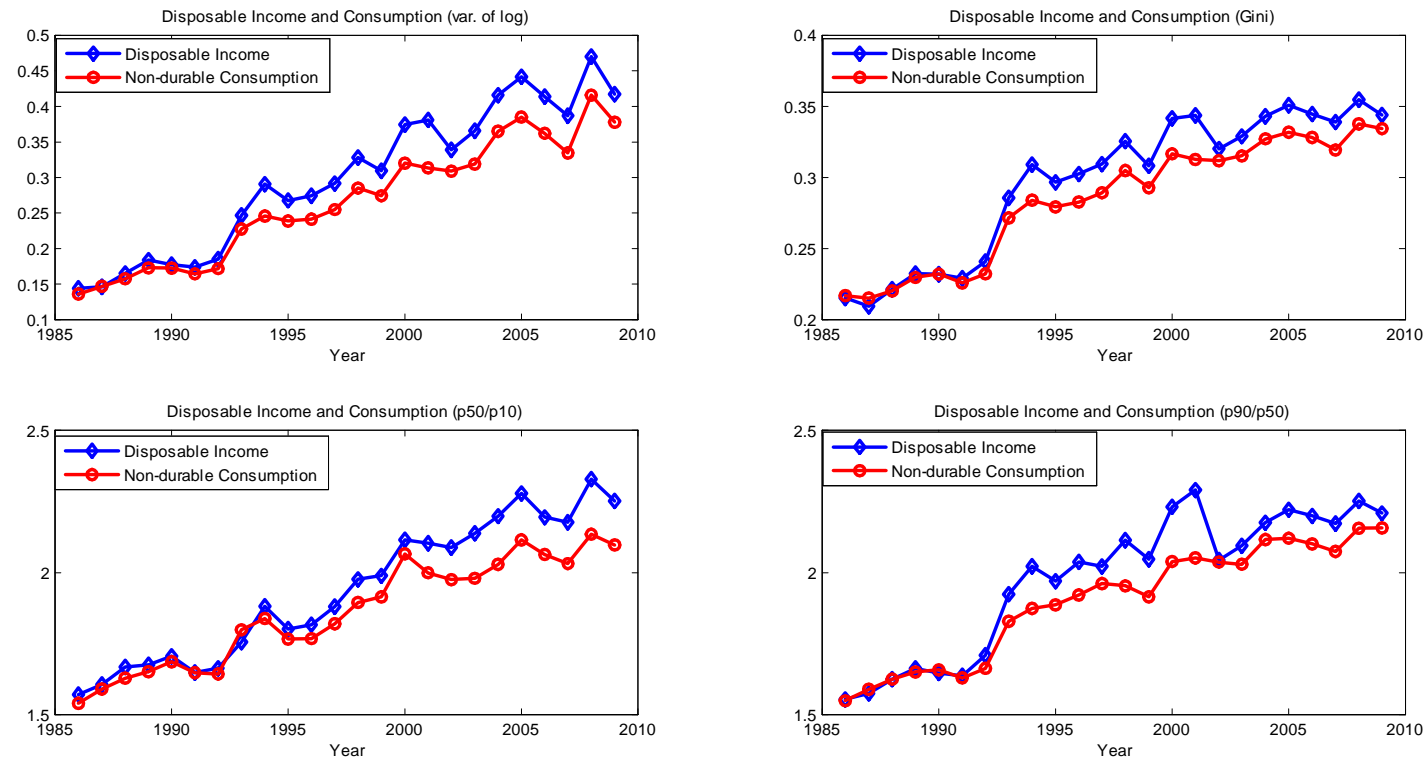
tion. After 1992, as the urban economic reform began to speed up and households had higher wages and hence increased their saving rate, nondurable consumption inequality started to diverge with income inequality. However, a surprising finding is that nondurable consumption still closely tracks with income inequality, which is very different from the pattern in the United States as documented in Krueger and Perri (2006) and Heathcote, Perri, and Violante, and the pattern in other countries documented in the RED 2010 special issue. $^{14}$

Robustness Check We have done a series of robustness checks on this striking co-movement relationship between income and nondurable consumption inequality. First, we redo Figure 9 using equivalized household disposable income and nondurable consumption for the period 1992-2009. Figure 10 shows the results. Using equivalent household scales slightly reduces the inequality measures. However, we still observe the excess co-movement between income and consumption inequality. Our most striking fact is robust to controlling for household composition.

Second, it is arguable that the UHS is subject to underreporting error and this error is more severe on income than on consumption. And it is also arguable that public sector workers in China would have much higher unreported income (so called "grey income") than private sector workers because they have much higher chances to be bribed and to receive in-kind transfers from the government. Therefore the reason why nondurable consumption inequality is very close to income inequality is that income inequality may be significantly underreported. Because private sector workers are subject to much less severe underreporting error in income, the relationship between income and consumption inequality should be more accurate when one only looks at the data for non-public sector workers.

Figure 11 shows the variance of $\log$ and Gini of disposable income and nondurable consumption for both public sector (government officials and SOE workers) and nonpublic sector workers. The top panels are measures for the public sector. The bottom panels are measures for the non-public sector. First, the bottom panels show that income and consumption inequality among non-public sector workers have a similar relationship as in Figure 9. Second, the public sector also shows a pattern similar to

\footnotetext{
${ }^{14}$ Probably the only country that has a similar relationship between disposable income and nondurable consumption inequality in China is Japan (see Lise and others 2014). However, even in Japan, the level of nondurable consumption inequality is substantially lower than income inequality, not as close as in the Chinese data. And Japanese data actually show negative co-movement between income and consumption inequality since the early 1990s (see Lise and others 2014 Figure 4.9).
} 
Figure 10: From Disposable Income to Nondurable Consumption: Equivalent Household Scale
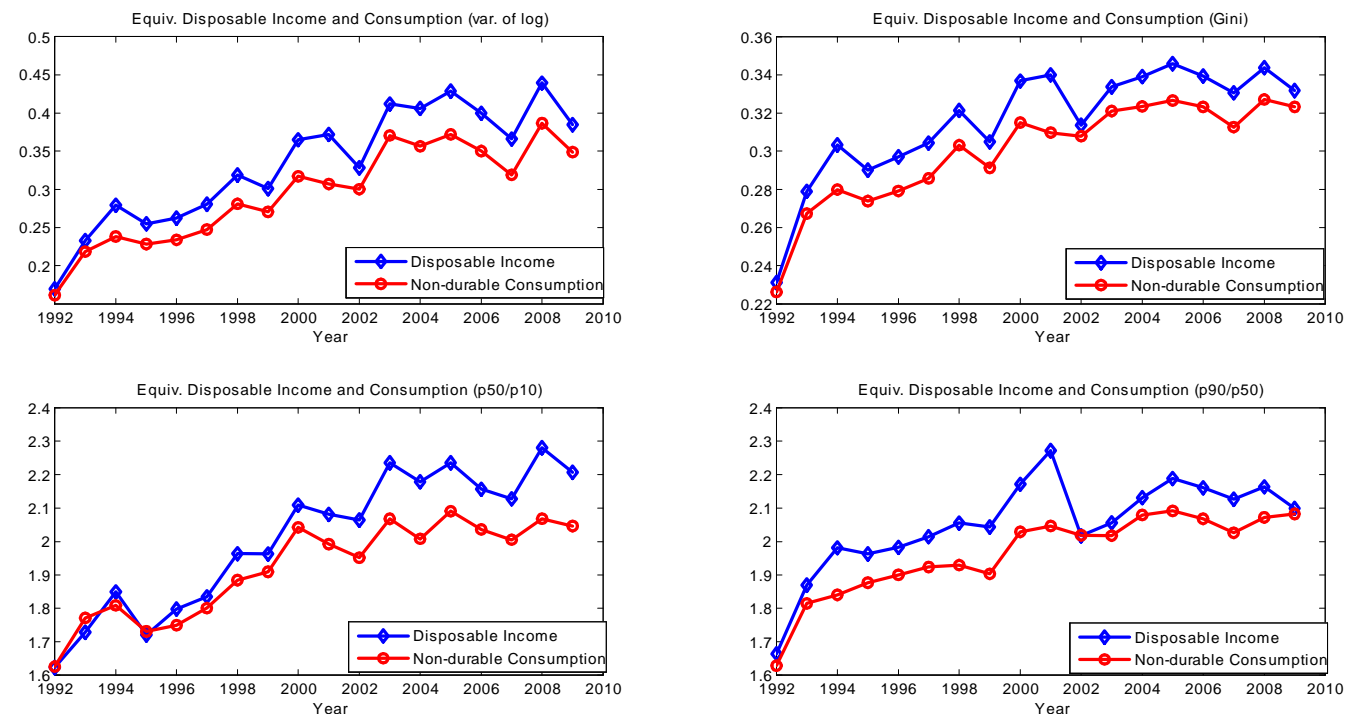
Figure 11: Income and Consumption Inequality: Public versus Private Sector
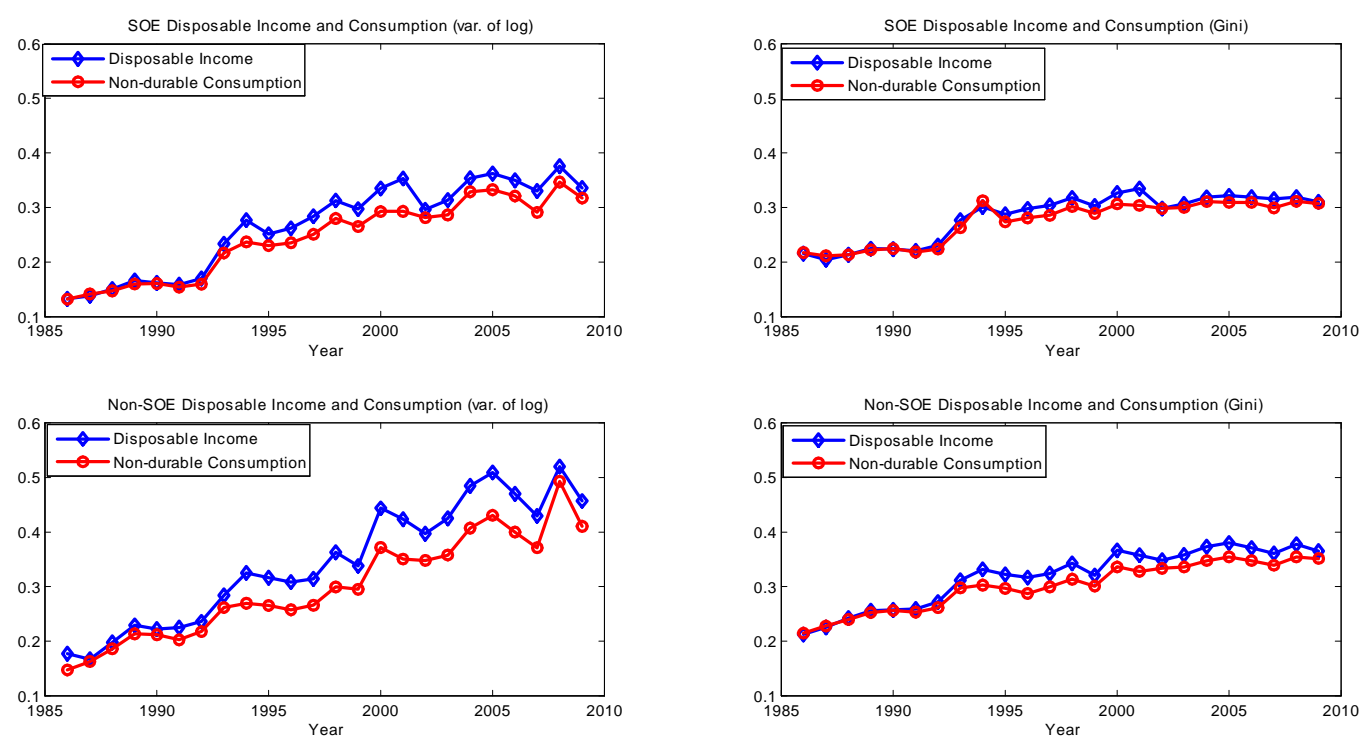

that for the non-public sector. There is no systematic difference in the relationship between income and consumption inequality across sectors. We thus conclude that the pattern in Figure 9 may not be mainly driven by the potential underreporting error in income.

We also check the evolution of disposable income and nondurable consumption inequality in different regions in China (Figure 12) and for different residence status (hukou versus migrated workers, see Figure 13). ${ }^{15}$ The relationship between income and consumption inequality remains largely unchanged for all these checks.

Finally, to check that the relationship between income and consumption inequality is not driven by the changes of provinces over time due to our access to the UHS data, we redo Figures 7 and 9 using the data from the nine provinces for which we

\footnotetext{
${ }^{15}$ Hukou refers to the household registration system in urban China. Hukou is linked to benefits on housing, education, health care, and so on. Migrated workers who do not have the registration card (hukou) tied to the place they are currently living are excluded from those benefits. In the UHS hukou information is available only for 2002-2009. Migrated workers are severely undersampled in the survey.
} 
Figure 12: Income and Consumption Inequality by Region
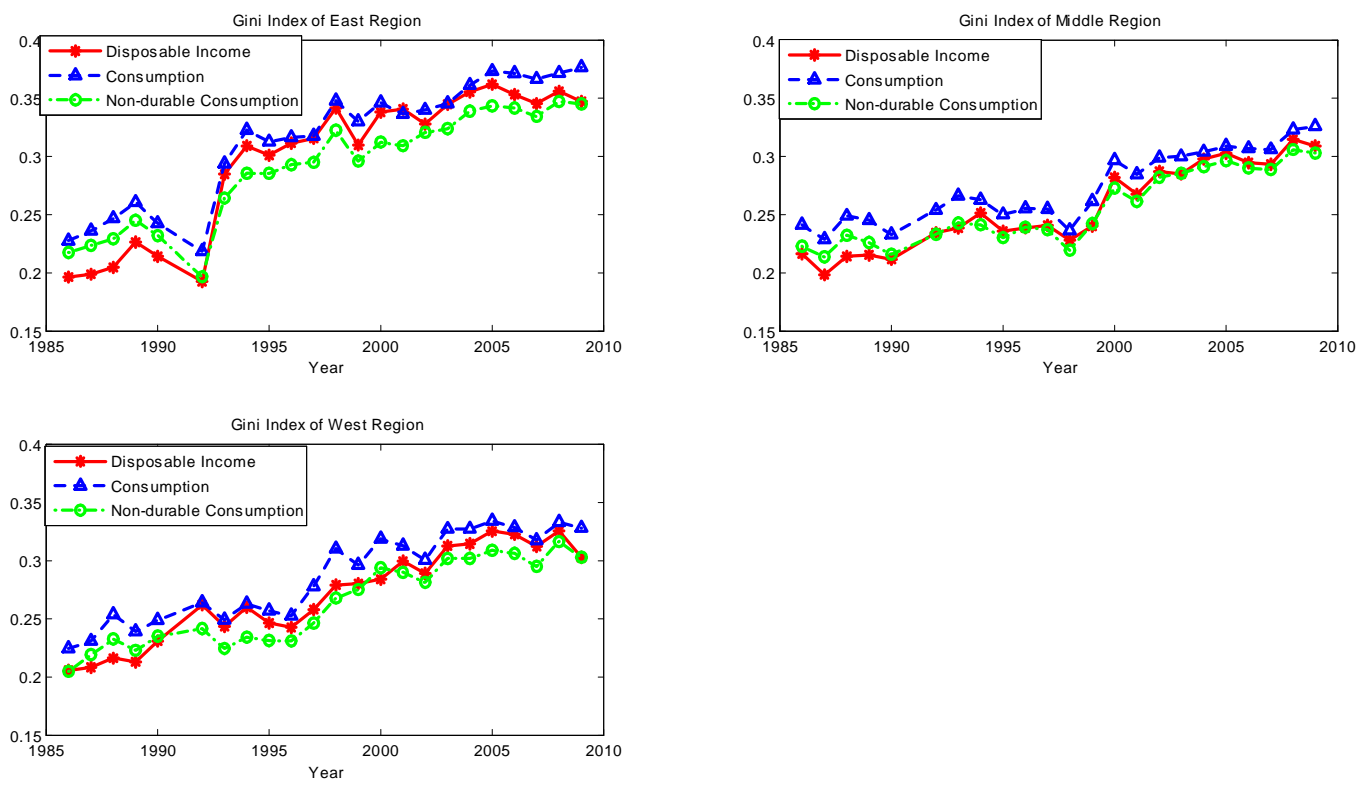
Figure 13: Income and Consumption Inequality: Hukou vs. Migrated Workers
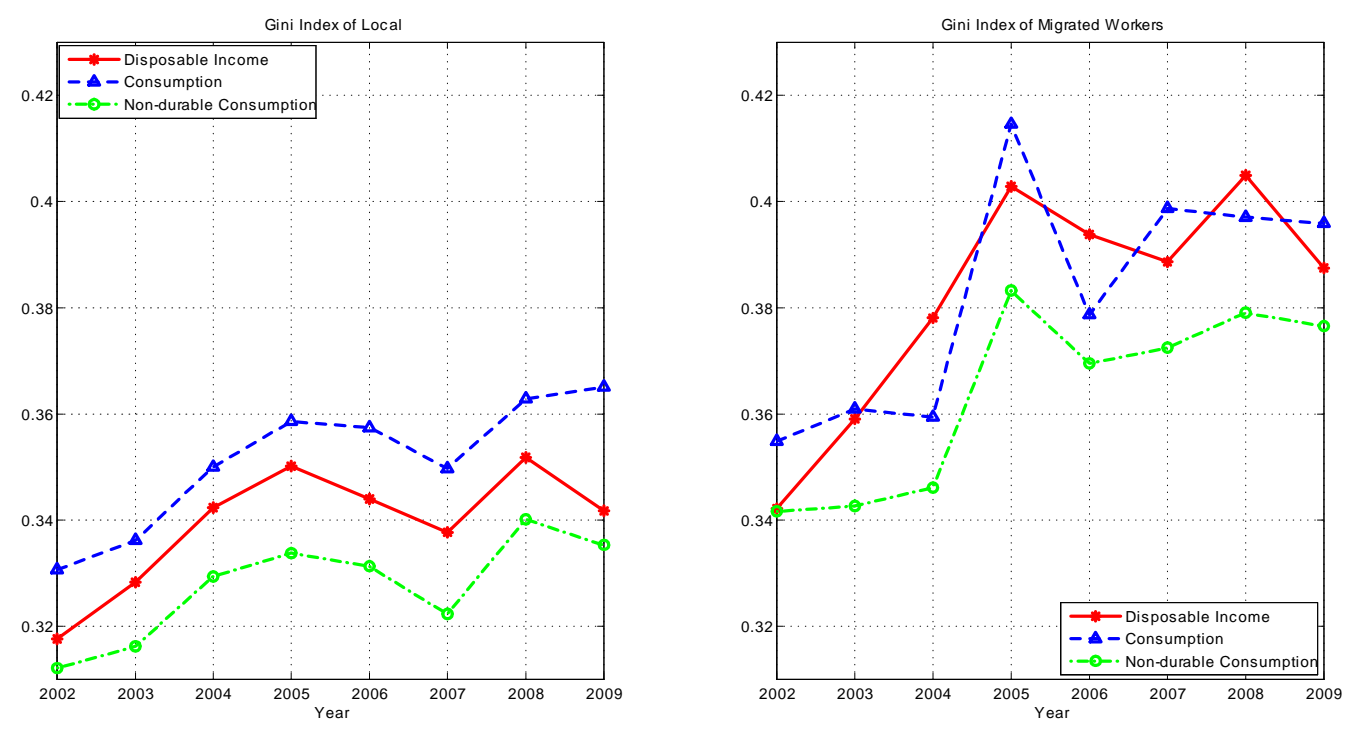

have data access through the whole time period $1986-2009 .{ }^{16}$ To save the space, we only look at the two dispersion measures: variance of log and Gini. The results are shown in Figure 14. The top panels show the relationship between total consumption and disposable income inequality. The bottom panels show disposable income and nondurable consumption inequality. Again, we see the results are similar to those in Figures 7 and 9 .

Decomposing Income and Consumption Inequality Following the methodology in Krueger and Perri (2006), we decompose the inequality (more precisely, variance of $\log$ ) of disposable income, total consumption, and nondurable consumption into "between-group" inequality and "within-group" inequality. "Between-group" inequality captures the part of inequalities that can be explained by observable household characteristics such as age, age ${ }^{2}$, education, location, and employment status. "Within-group" inequality is the residual variance.

\footnotetext{
${ }^{16}$ The nine provinces are Beijing, Liaoning, Zhejiang, Anhui, Hubei, Guangdong, Sichuan, Shanxi, and Gansu.
} 
Figure 14: Income and Consumption Inequality: Nine Provinces for 1986-2009
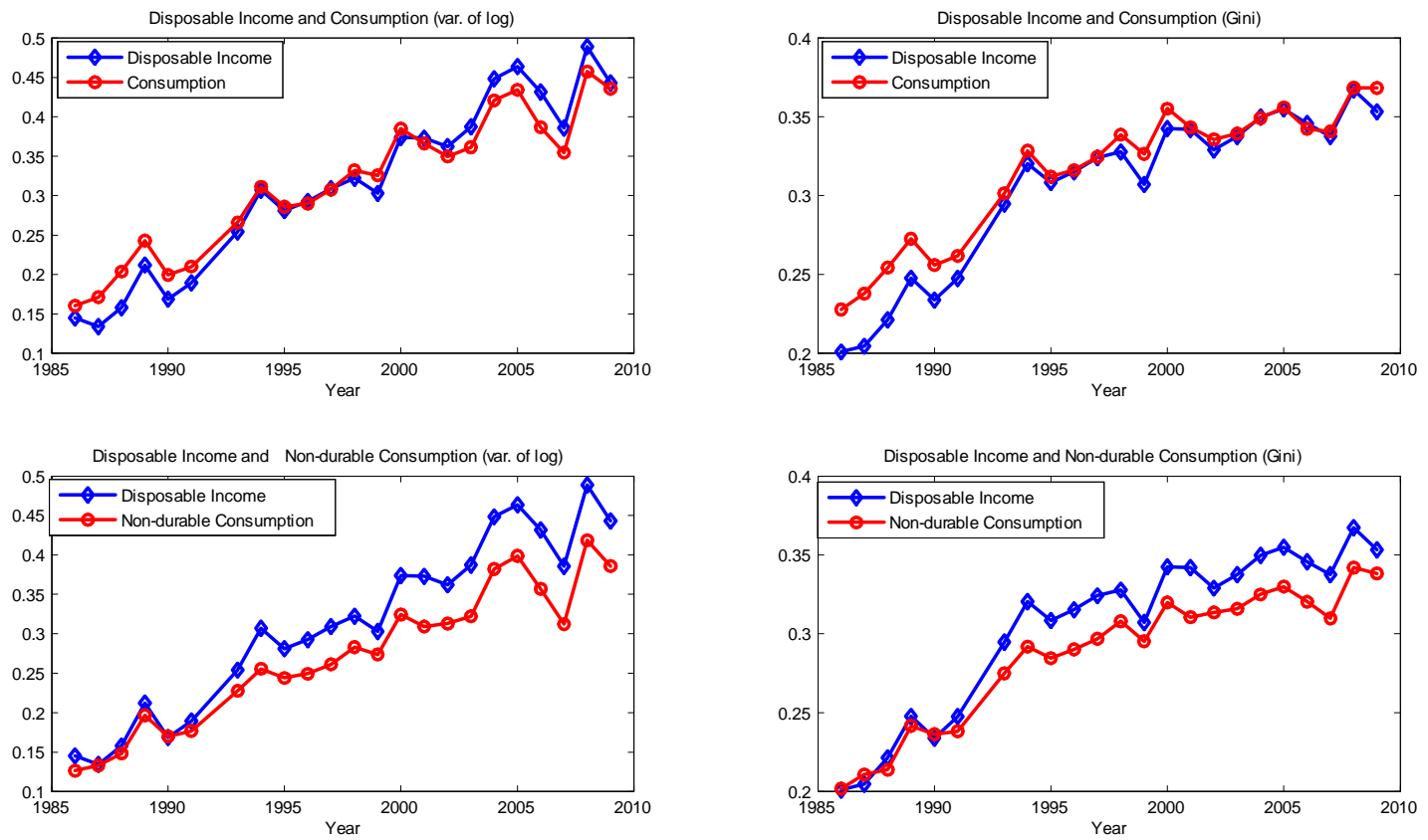
Figure 15 shows the evolution of "between-group" and "within-group" inequality of disposable income, consumption, and non-durable consumption. We have several findings. First, "between-group" inequality is dwarfed by "within-group" inequality in terms of magnitude. For example, variance of log for disposable income increased from around 0.04 in 1986 to about 0.12 in 2009, while "within-group" inequality increased significantly from slightly above 0.1 in 1986 to 0.3 in 2009 . Therefore the increase in income and consumption inequality is mainly driven by "within-group" inequality. Second, in terms of the level of inequality, for "between-group" inequality, we see disposable income has the highest variance. Next is total consumption. Nondurable consumption is the lowest. However, for "within-group" inequality, things are quite different. The variance of total consumption is uniformly higher than that

of disposable income; while variance of nondurable consumption is quite close to that of disposable income, although it is lower than that of income most of the time. Third, in terms of co-movement between income and consumption inequality, both "between-group" and "within-group" inequality exhibit a strong co-movement behavior, with the co-movement being even stronger in "within-group" decomposition. Overall the decomposition shows that the relationship between income and consumption inequality is mainly determined by "within-group" not "between-group." The increasing within-group consumption inequality speaks against a complete market model as emphasized in Krueger and Perri (2006). And the close track of withingroup consumption inequality to within-group income inequality is also a clear sign of severe lack of within-group risk sharing. That said, to understand the driving force behind the co-movement of income and consumption inequality, we have to look at the residual income which is not captured by observable household characteristics.

\section{A.4 Wealth Inequality}

Finally, we would like to demonstrate the evolution of wealth inequality in urban China. Unfortunately the UHS does not have wealth data. We therefore turn to the CHIP data for the analysis. The CHIP only has wealth data in its 1995 and 2002 waves. The measure of wealth is financial net worth, which is the total financial assets minus total household debt. The CHIP data show that from 1995 to 2002, the Gini coefficient of financial net worth had increased from 0.71 in 1995 to 0.81 in 2002. Castaneda and others (2003) report that the wealth Gini in the United States is 0.78 based on a 1992 survey of consumer finances (SCF) data. The Chinese number we obtain here is close to that in the United States. 
Figure 15: Between-group versus Within-group Inequality
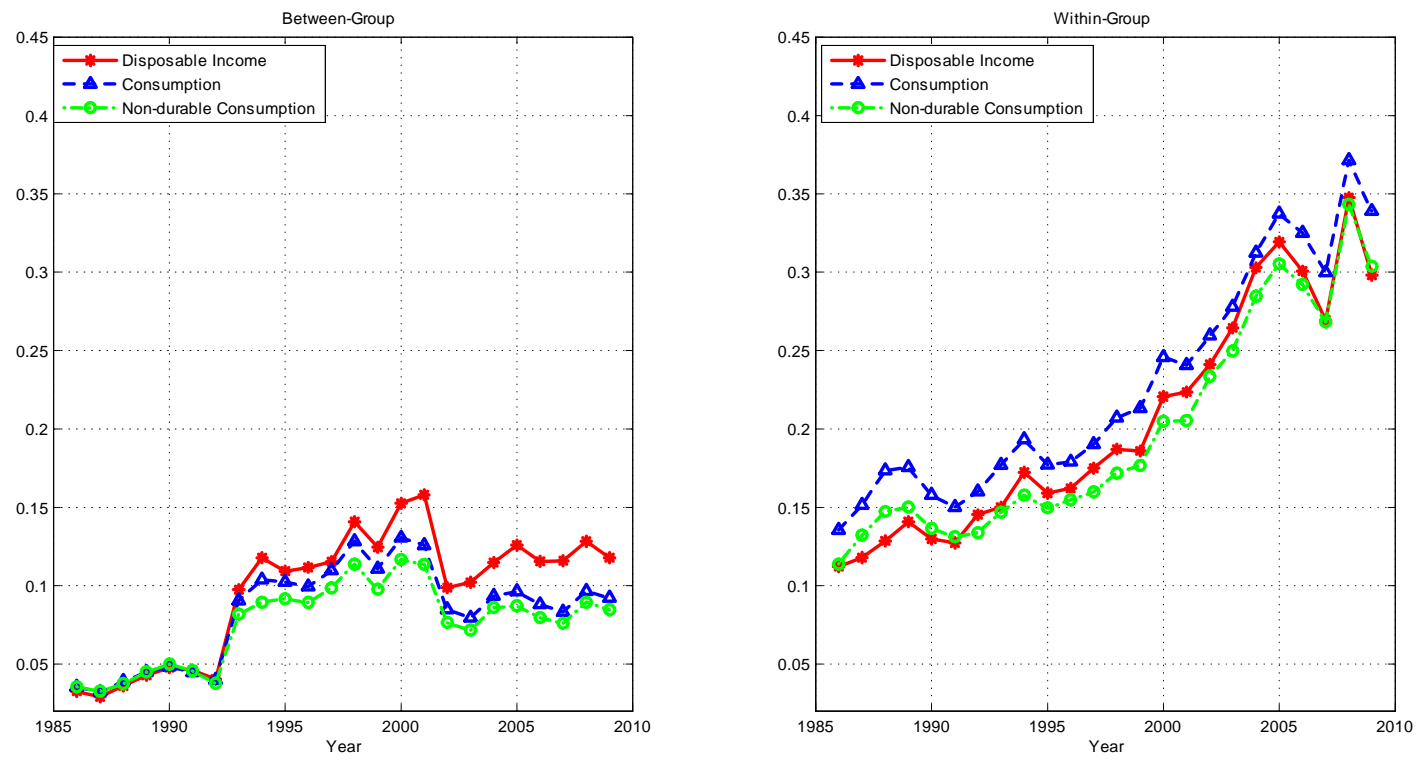
Figure 16: Individual Earnings Inequality
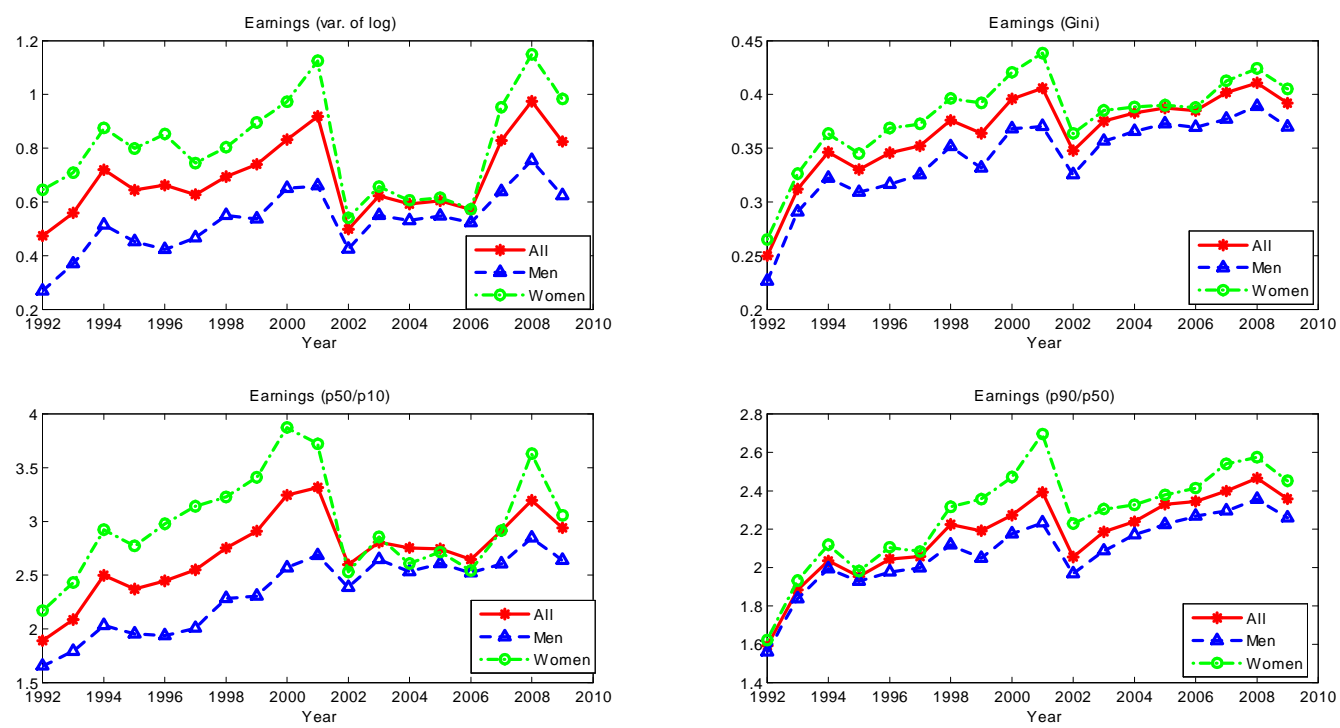

\section{B Individual-level Inequality}

We now turn our attention to individual-level inequality. All empirical results for individual-level inequality are based on sample C. The only available individual-level variable in the UHS is earnings. Figure 16 shows the evolution of individual earnings as a whole and also by gender. As mentioned earlier, individual earnings data in the UHS are only available from 1992. As shown in panel B in Figure 16, earnings Gini has been increasing quite significantly from about 0.25 in 1992 to about 0.40 in 2009 . The magnitude is about the same as that for the household level as shown in Figure $2 .^{17}$

\footnotetext{
${ }^{17}$ Notice that variance of both the $\log$ and the P50/P10 ratio show a dramatic drop in 2002 and a significant jump in 2007. The Gini coefficient and P90/P50 ratio also show a smaller drop in 2002. We suspect that those changes are owing to changes in the UHS questionnaire in these two years.
} 


\section{INEQUALITY OVER LIFE CYCLE}

The previous section focuses on the evolution of cross-section economic inequality over time. We can draw implications of risk sharing across individuals and also across time from the data pattern we found. What about inequality over the life cycle in China? How would the Chinese insure against income shocks over the life cycle? To answer these questions, we use the methodology in Deaton and Paxson (1994) to estimate the age profiles for inequality in earnings, income, and consumption, based on Sample B in the UHS data.

Following Heathcote, Perri, and Violante (2010), we denote $m_{a, c, t}$ be a cross-sectional moment of interest (e.g., the variance of log income) for the group of household heads with age $a$ belonging to birth cohort $c$ at year $t$. We run the following two regressions separately to control for year effects and cohort effects respectively:

$$
\begin{aligned}
& m_{a, c, t}=\beta_{a}^{\prime} D_{a}+\beta_{t}^{\prime} D_{t}+\varepsilon_{a, c, t} \\
& m_{a, c, t}=\beta_{a}^{\prime} D_{a}+\beta_{c}^{\prime} D_{c}+v_{a, c, t}
\end{aligned}
$$

where $D_{a}, D_{t}$, and $D_{c}$ are vectors with entries corresponding to age, year, and cohort dummies.

Panel A in Figure 17 reports $\beta_{a}$ for all ages in equation (1) which controls for year effects. ${ }^{18}$ Panel B reports $\beta_{a}$ for all ages in equation (2) which controls for cohort effects. Results in Figure 17 worth discussing. First, as discussed in Heathcote, Perri, and Violante (2010) for the U.S. data, we also find that in Chinese data the magnitude of increases in life cycle inequality is sensitive to which effect is controlled for. For example, the variance of log household earnings increases about 2.5 times faster over the entire life cycle when controlling for the cohort effect than the year effect. The increase of disposable income and non-durable consumption inequality over the life cycle is also much smaller when controlling for the year effect. Second, the order of rising inequality over the life cycle is also similar to that in the U.S. data, as in Heathcote, Perri, and Violante (2010). We see that the variance of log household earnings rises over the life cycle far more significantly than that of disposable income, which in turn rises more than the variance of log nondurable consumption. However, the main difference between the pattern in Figure 17 and the one shown in the

\footnotetext{
${ }^{18}$ Following Heathcote, Perri, and Violante (2010), we group observations in 5-year age bins. Therefore data start from age 27 which is the midpoint of the first 5-year age group (25-29). We however do not normalize data at zero for first age group.
} 
Figure 17: Inequality over the Life Cycle
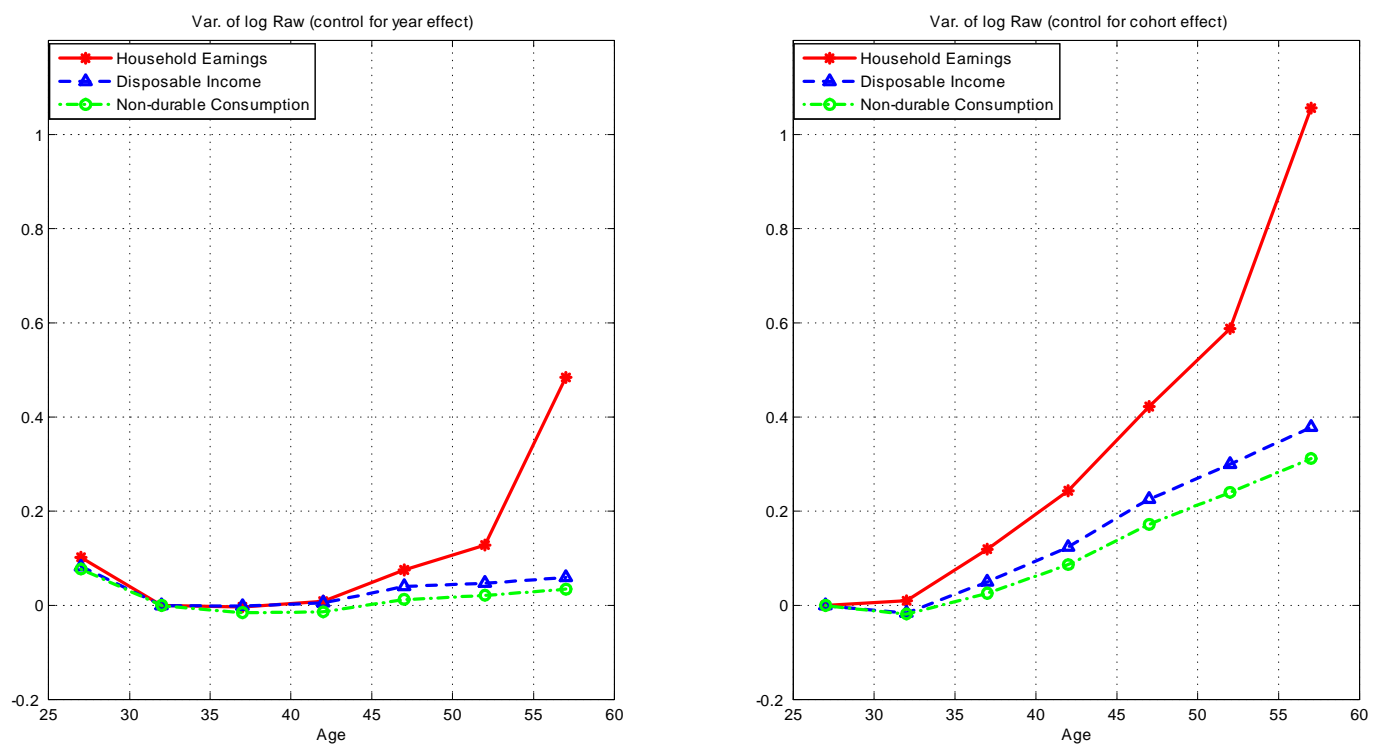

U.S. data (Figure 14 in Heathcote, Perri, and Violante 2010) is that nondurable consumption inequality still closely tracks income inequality over the life cycle in urban China; while in the United States, consumption and income inequality diverge as an individual ages. In other words, unlike the U.S. data, which show that the consumption inequality profile is concave over the life cycle, the Chinese data show a convex consumption inequality profile, similar to that of income. The co-movement of income and consumption inequality also appears over the life cycle. This indicates that the ability to insure against an idiosyncratic income shock over the life cycle is also quite limited for Chinese households.

To check the robustness of the results in Figure 17, we also redo the figure using equivalized variables. Figure 18 shows that the main pattern in Figure 17 remains when controlling for equivalent household scale. 
Figure 18: Inequality over the Life Cycle: Equivalent Household Scale
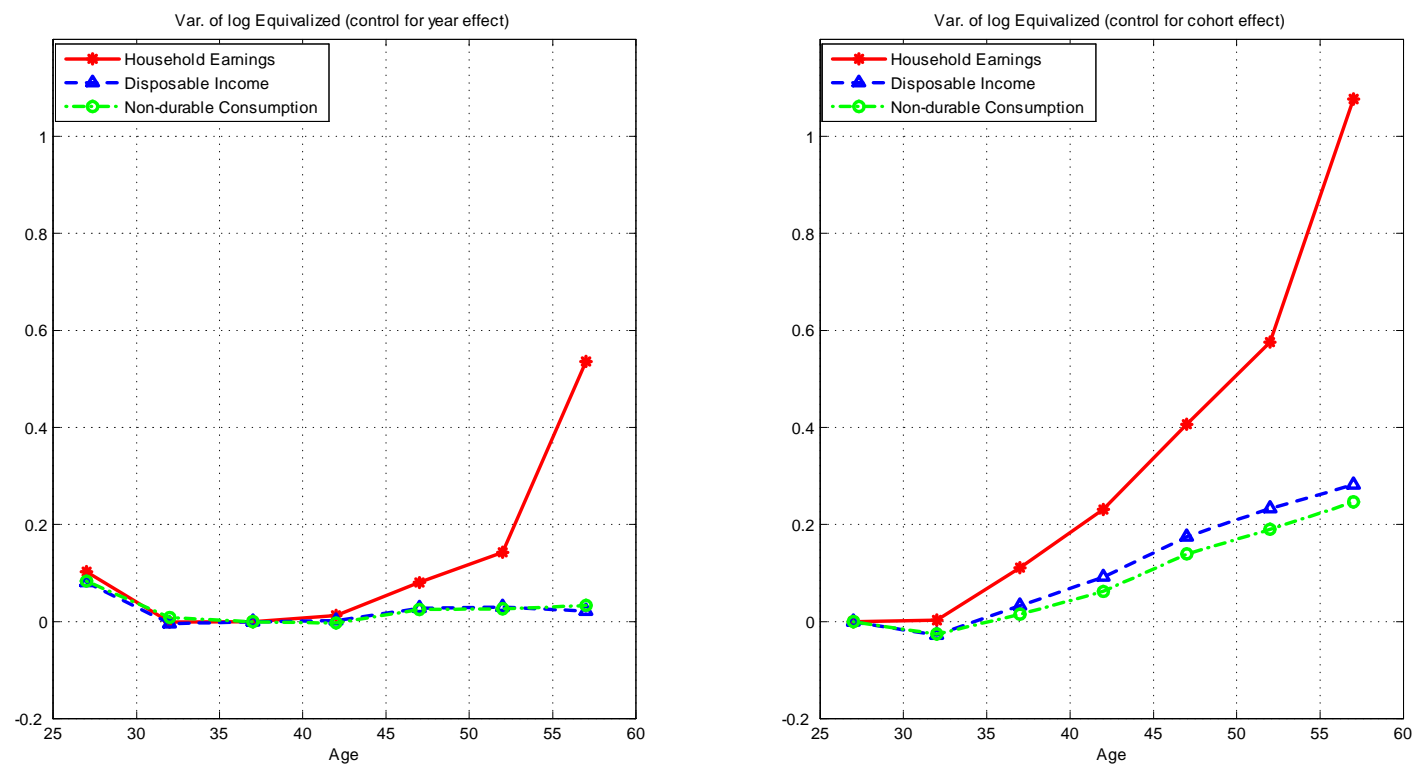


\section{INCOME DYNAMICS}

The most striking fact about inequality in urban China that we have found so far is that over time, we found very limited risk sharing across individuals and no sign of significant improvement in risk sharing over time. Therefore consumption inequality closely tracks with income inequality. In addition, this co-movement also exists over the life cycle.

What could be the reason behind the surprising co-movement between income and consumption inequality in China? One possible explanation could be that it is a sign of the prevailing existence of "hand-to-mouth" consumers. In other words, a large share of consumers in the population just simply consume what they earn. In this case, consumption would be roughly equal to income. Therefore their variance is also roughly equal.

This theory obviously implies that the saving rate should be close to zero among households. The average household saving rate in the UHS data, however, is close to 20 percent over time. Apparently we tend to reject the theory at large. To look further into the story, we plot the changes in the household saving rate over time, by income quintiles as shown in Figure 19. Except in the lowest income quintile, we see that the household saving rate is significantly positive in all income quintiles. And the saving rate is higher as income quintile moves up. In addition, what is more important is that for all other income quintiles, the saving rate has been increasing over time. ${ }^{19}$ Therefore at most we can only claim that we find some evidence supporting "hand-to-mouth" consumers in the lowest income quintile. ${ }^{20}$ However, we reject this explanation as the main driving force behind the co-movement of income

\footnotetext{
${ }^{19}$ A related possible explanation for the co-movement is a "target saving rate." In other words, Chinese might target their saving rate at a constant level. Once they have their income earned, they first save a constant fraction of their income and then use the remaining portion for consumption. Then their consumption is a constant fraction (call it $\alpha$ ) of income as well. $C=\alpha Y$ then implies $\operatorname{Var}(C)=\alpha^{2} \operatorname{Var}(Y)$. This implies that consumption inequality is lower than income inequality. But both co-move together. Figure 19 obviously refutes this theory as well because we observe that the saving rate in all income quintiles increases significantly over time. Therefore $\alpha$ declines over time, which should make consumption and income inequality less connected over time, which we do not observe in the data.

${ }^{20}$ The UHS unfortunately does not have wealth data to help us differentiate between wealthy hand-to-mouth (HtM) and poor HtM consumers as investigated in Kaplan, Violante and Weidner (2014). But because we control for the income quintiles here in Figure 19, our guess is the HtM consumers in the lowest income quintile are most likely poor HtM ones.
} 
Figure 19: Household Saving Rate by Income Quintiles

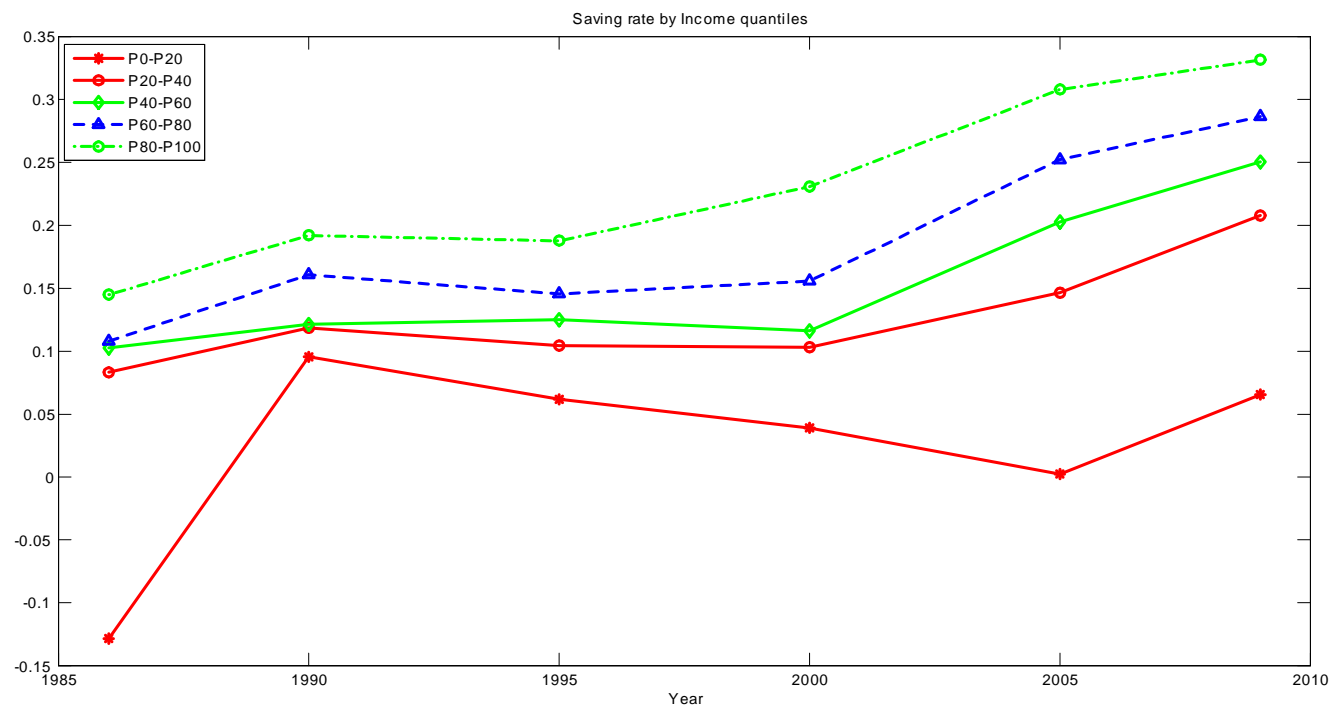

and consumption inequality among the majority of individuals in the society.

Our second explanation lies in the changes in underlying income shock structure. The literature shows that it is much harder for households to insure against idiosyncratic permanent income shocks than against transitory income shocks (Blundell, Pistaferri and Preston 2008). Therefore a possible explanation for why consumption inequality closely tracks with income inequality is that rising permanent income shocks dominates transitory income shocks over time. The uninsurable part of idiosyncratic income shocks thus increases over time, which impedes efficient risk-sharing among households to smooth consumption and hence leads to a tight co-movement between income and consumption inequality.

To test this theory, we first explore the rotating panel structure of the UHS as described in Section 3.1 to construct short panels of data at the household level. Appendix B provides details of the construction. We then use the constructed data to estimate a permanent-transitory earnings dynamic model. 


\section{A Model}

We estimate a simple statistical model following Heathcote, Perri, and Violante (2010). We first run a Mincerian regression to regress log earnings from the data constructed above against household characteristics such as age, age ${ }^{2}$, education, employment status, and provincial dummies. We run this regression year by year. Let $w_{i, c, t}$ be the residual earnings for individual $i$ of cohort $c$ at year $t$ from the regressions; we then estimate a permanent-transitory wage dynamic model as follows

$$
\begin{aligned}
w_{i, c, t} & =z_{i, c, t}+\varepsilon_{i, c, t} \\
z_{i, c, t} & =z_{i, c, t-1}+\eta_{i, c, t}
\end{aligned}
$$

where $z_{i, c, t}$ is the permanent component of income process and $\varepsilon_{i, c, t}$ is the transitory income shock. $\eta_{i, c, t}$ is the innovation to permanent income process. We assume that $\varepsilon_{i, c, t}$ and $\eta_{i, c, t}$ are uncorrelated over time and i.i.d. across individuals, with zero mean and variances $\sigma_{\varepsilon, t}$ and $\sigma_{\eta, t}$. By assumption, these variances are time-varying but not cohort-dependent.

We follow the literature on estimating two specifications of the model. One uses moments based on the income growth rate-here the first-differences in log earnings. The other uses moments in the log earnings level. Appendix C provides a detailed description of the estimation strategy for two methods. We refer readers to Heathcote, Perri, and Violante (2010) for further details of the methods.

\section{B Findings}

We plot the estimated variances of permanent and transitory income shocks (that is, $\sigma_{\eta, t}$ and $\left.\sigma_{\varepsilon, t}\right)$ based on both methods in Figure 20. As we explain in Appendix B, 
Figure 20: Transitory versus Permanent Income Shocks
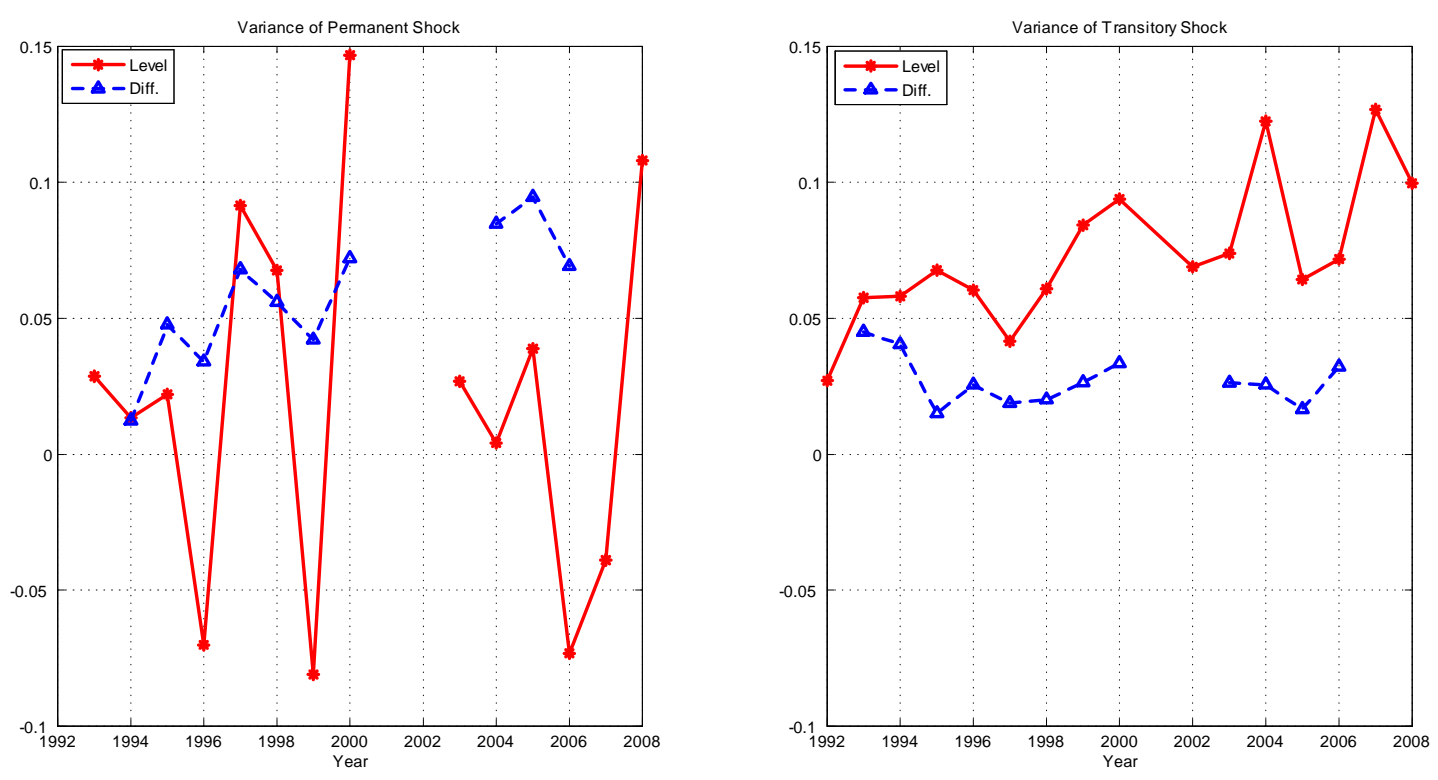

we focus on the time period from 1992 to 2007 because of our data limitation. $^{21,22,23}$

There are some similarities and some dissimilarities in income shocks between China and advanced economies such as the United States. What is similar to the United

\footnotetext{
${ }^{21}$ To test the robustness of our results in Figure 20 on sample selection, we also rerun the estimation for two methods using the panels that relax age restriction. See Appendix B for the construction of this relaxed age restriction sample and the associated results. We find that our results are largely robust to relaxing the age restriction.

${ }^{22}$ Because we cannot have a three-year panel for 2001-2003 due to the major change to the questionnaires in 2002, any term that involves $\Delta w_{i, c, 2002}$ and $\Delta w_{i, c, 2003}$ in the estimation equations (3) and (4) becomes unavailable. Therefore we cannot estimate $\sigma_{\eta, t}$ for the years 2001, 2002, and 2003 and we cannot estimate $\sigma_{\varepsilon, t}$ for years 2001 and 2002 using the "difference" method. Similarly, because we do not have the three-year panel for the 1991-1993 period because of the change to the questionnaires in 1992, we are not able to estimate $\sigma_{\eta, t}$ for 1993 and we cannot estimate $\sigma_{\varepsilon, t}$ for 1992 using the "difference" method. We refer readers to Appendix C for more details.

${ }^{23}$ By similar logic, because we cannot have a two-year panel for 2001-2002, any term involves $\operatorname{cov}\left(w_{i, c, 2002}, w_{i, c, 2003}\right)$ in the estimation equations (5) and (6) becomes unavailable. Therefore we cannot estimate $\sigma_{\eta, t}$ for 2001 and 2002 and we cannot estimate $\sigma_{\varepsilon, t}$ for 2001 using the "level" method.
} 
States is that the variance of transitory shocks is higher (for most of the time period) than that of permanent shocks under the "level" method, while it is exactly opposite under the "difference" method. We also find that estimates based on the level method differ significantly from those based on the difference method, which is a common problem for countries examined in the RED special issue, as emphasized in Heathcote, Perri, and Violante (2010).

We also notice that as with the U.S. data, the level-based estimates of variance of permanent income shocks are negative in some years. Agreeing with Heathcote, Perri and Violante (2010), we view it as a sign of the mis-specification of the level method. However, in contrast to the U.S. data, permanent income shock estimated by the level method is far more volatile. The difference method gives us a much more reasonable estimation than the level method (see Figure 20). In addition, the difference method of estimating the income process is commonly used in labor economics research (see, for example, Blundell, Pistaferri, and Preston 2008). We therefore think that the difference method gives a more accurate estimation of income process in China.

By looking at the results of the difference method, we notice that the biggest difference in income shock between China and United States (also Japan) is that we observe a dramatic increase in variance of permanent income shock. As shown in

panel A in Figure 20, the difference method tells us that $\sigma_{\eta}$ has increased from 0.012 in 1994 to 0.095 in 2005; that is, almost eight times. We have never seen an increase of this size in $\sigma_{\eta}$ in any advanced economies covered by the RED special issue and Japan (see Figure 6.1 in Lise and others 2014). Although permanent income shock shows a dramatic increase after the early 1990s in China, transitory income shock does not show any secular change (or maybe we should say there is a slight decline trend). Owing to the drastic increase of the permanent income shock, the composition of the income shock process has been fundamentally changed. In 1994, transitory income variance was 0.04 , about three times bigger than permanent income variance. However, by 2005, transitory income variance was only $0.017,5.5$ times smaller than permanent income variance.

\section{Blaming Transition?}

Taking into account that individuals can only partially insure against permanent income shocks and almost fully insure against transitory income shocks (Blundell, Pistaferri, and Preston 2008), the underlying change in the composition of the income 
shock implies that it is getting more difficult to share risk across individuals over time, which might lead to a synchronization between consumption and income inequality. We believe that this could be a plausible story behind the observed co-movement of income and consumption inequality. ${ }^{24}$

But what caused such a dramatic increase in permanent income variance? As shown in Section 2, the vast effort of economic transformation to push the economy toward a more market orientation took place since the mid-1990s. A large number of SOEs have been either privatized or simply shut down. SOE workers therefore faced a tremendous and systematic increase in uncertainty associated with the SOE reform (see He and others 2015). During the economic transition, disadvantaged groups such as less educated and relatively older workers faced a higher chance of being laid off and hence were hurt more severely by the transition (Appleton and others 2002). Motivated by these facts, we further decompose the income process estimation by the difference method along three dimensions: enterprise ownership, education and age. Figures 21-23 show the results.

Figure 21 shows the permanent and transitory income variances by the ownership of the firm where a household head works. As one would expect, workers of nonSOEs face a significantly higher and more volatile income shocks than SOE workers. However, the substantial increase in permanent income variance that SOE workers faced from 1994 to 2000 could be a consequence of the SOE restructuring reform, as previously mentioned. As the economic transition goes forward, the share of SOEs in terms of both output and employment in the economy shrinks dramatically (as seen in Table 2). This implies that as time goes by, overall urban workers more likely work for non-SOEs and hence face a higher permanent income shock, as we observe in Figure 20.

Figure 22 demonstrates the permanent and transitory income variances by the household head's highest level of education, using a high school diploma as a cut-off. For both education groups, we see the time trends of permanent and transitory income variance are consistent with the ones in Figure 20 for the whole economy. In addition, the less-educated group ("high school and below") has higher permanent and transitory income variance than the group with at least an associate degree.

\footnotetext{
${ }^{24}$ Santaeulalia-Llopis and Zheng (2015) apply the Blundell, Pistaferri, and Preston (2008) methodology to the Chinese health and nutrition survey (CHNS) data, and estimate the partial insurance coefficient of the permanent income shock. They find that consumption insurance in China did deteriorate dramatically from 1989 to 2009.
} 
Figure 21: Income Shock: SOEs vs. POEs
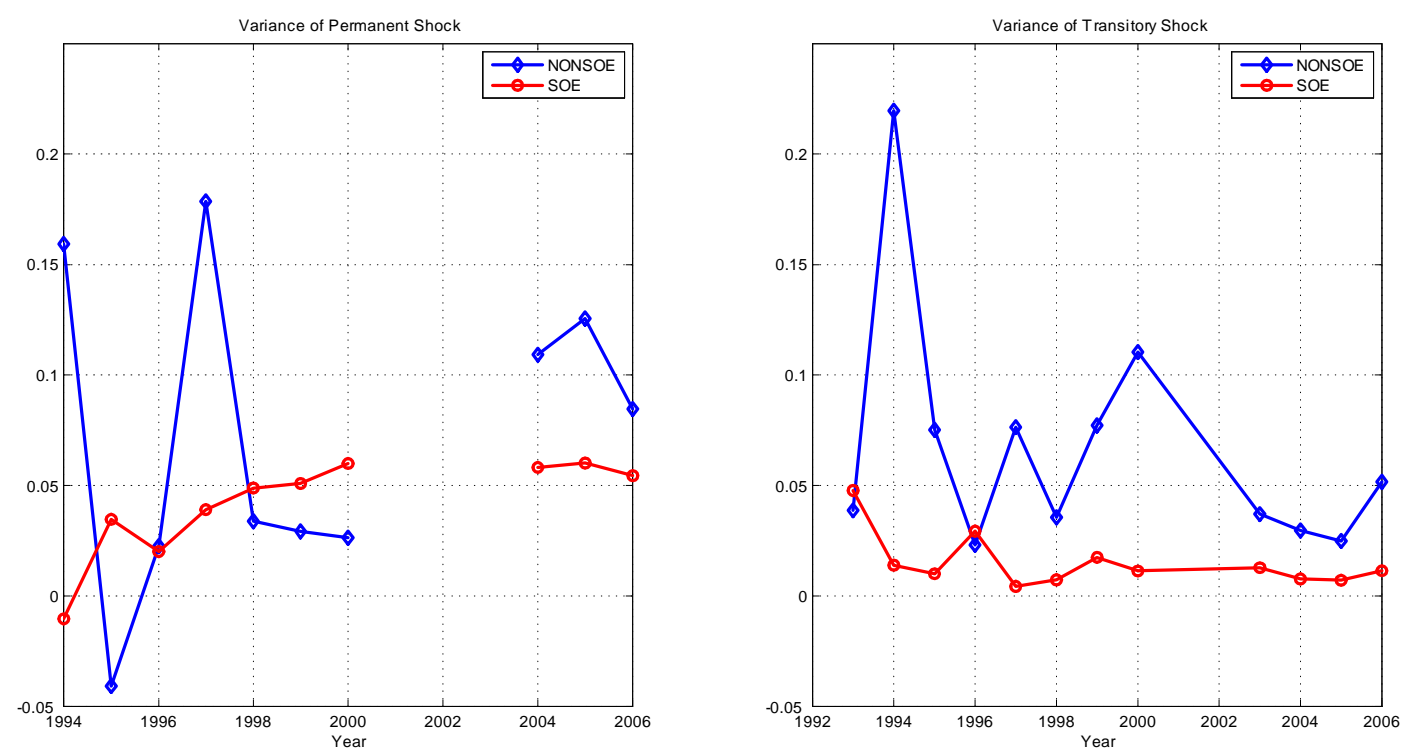

Finally, Figure 23 exhibits the permanent and transitory income variances by the household head's age. We divide the age into two groups: ages 20-39 and 40-60. We find that the permanent income shock still shows an upward time trend for both groups. And overall the older group tends to have a relatively higher and more volatile permanent income variance.

In summary, the decomposition not only gives a robust check to the main message in Figure 20, but also further identifies the groups who bear higher income risk during the economic transformation. The estimation tells us that non-SOE, less-educated, and older workers bear higher income risk. They, in particular, face especially increasing permanent income shocks over time. These people are the ones being hurt most during the economic transition in urban China. The decomposition exercise thus helps us to establish a link between the economic transition and the changing income shock structure.

The findings in Figures 20-23 together provide a big picture for understanding what caused the rising permanent income shock. They provide some suggestive evidence that the economic transformation might be an important driver of that fundamen- 
Figure 22: Income Shock by Education
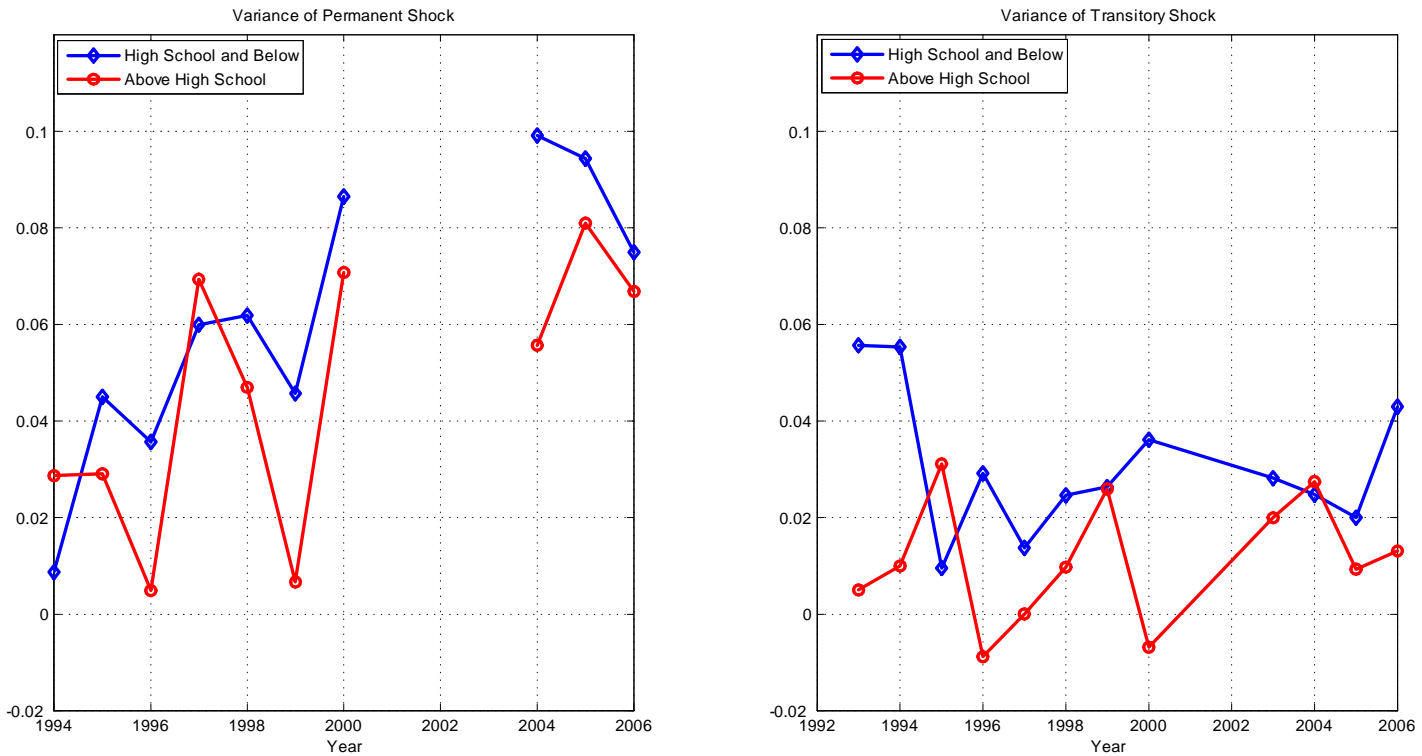
Figure 23: Income Shock by Age
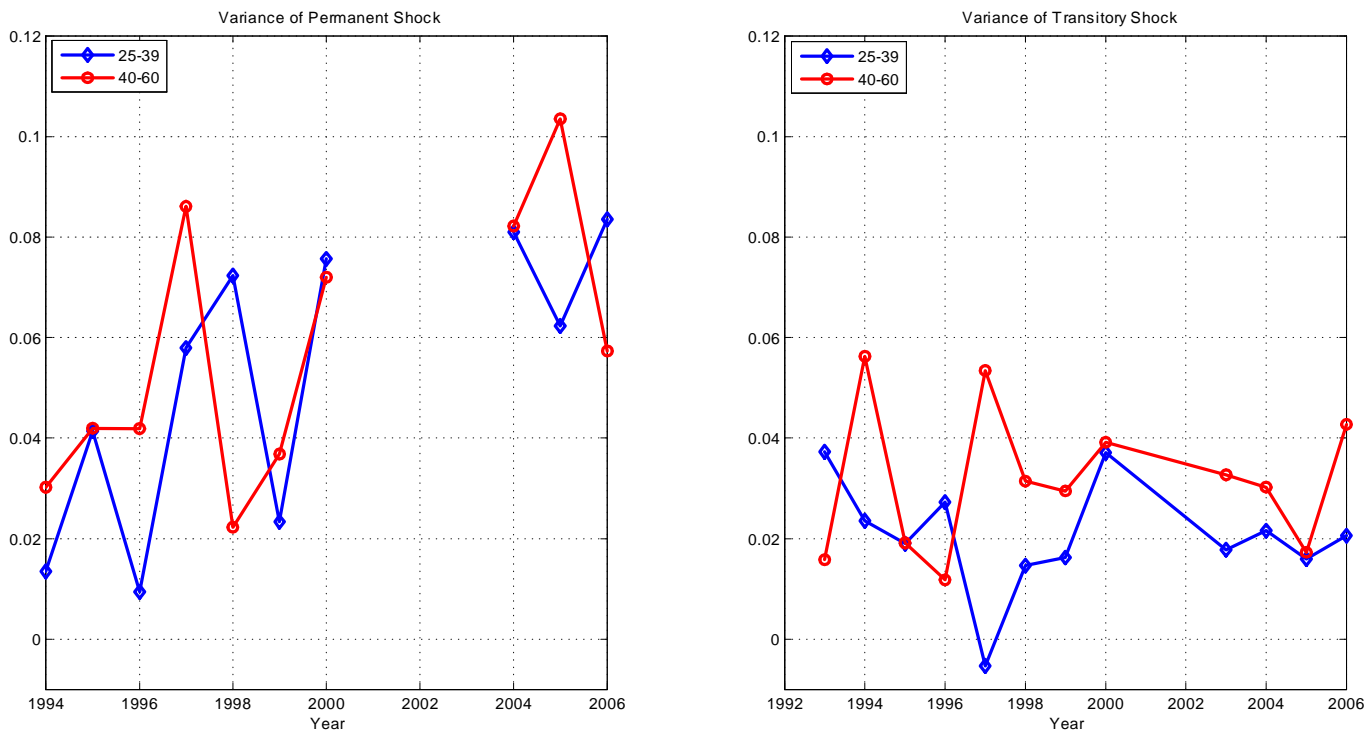
tal change in the underlying income shock structure. In that sense, we think the co-movement of income and consumption inequality in China could be a tale of transition. The transition in urban China created tremendous uncertainty and led to a significant increase in uninsurable income shock, which passed on rising consumption inequality resulting from the lack of insurance against the permanent income shock, as emphasized in Blundell, Pistaferri, and Preston (2008). To test how quantitatively important this potential channel is in explaining the pattern observed in Figure 7 goes beyond the scope of the current paper. But it is the next step in our research agenda.

\section{CONCLUSION}

This paper provides a comprehensive empirical study of earnings, income, and consumption inequality in urban China from 1986 to 2009, using unique micro-level survey data-the Urban Household Survey (UHS). We document a drastic increase in economic inequality for the sample period. For example, the variance of log household disposable income in China increased from about 0.14 in 1986 to about 0.43 in 2009; that is, threefold during 24 years. We also find a striking fact that consumption inequality closely tracks with income inequality over time, which seems go against the standard consumption smoothing theory. Following the literature, we estimate inequalities over the life cycle and find that the co-movement between income and consumption inequality also exists over the life cycle. This unique fact has not been found in the study of other countries (see, for example, RED 2010 special issue).

Why does consumption inequality closely track income inequality over time in urban China? One possible explanation is that individuals are just hand-to-mouth consumers; that is, they just simply consume their income. Looking at the changes in the household saving rate by income quintiles over time, we only find vague supporting evidence in the lowest income quintile. We therefore largely tend to reject this hypothesis. Another possible explanation is that there is a fundamental change in idiosyncratic income shock structure which makes it more difficult for individuals to insure against income shocks. To test this theory, we estimate the income process in China and find that there is a dramatic increase in the idiosyncratic permanent income shock after the mid-1990s. And the increasing non-insurable permanent income shock dominates the insurable transitory income shock as time goes by. We make further effort to investigate what causes the substantial increase in the permanent income shock. We find that the vulnerable groups that were more severely affected 
by the urban economic transition face a higher and more volatile permanent income variance. Therefore we link the economic transition to the changing income shock structure. We think this changing income shock structure, the effect of economic transition, could be the main driving force behind the seemingly puzzling fact of the co-movement between income and consumption inequality.

The lesson we learn from our investigation of economic inequality in urban China is that economic transition and structural transformation could tremendously change the underlying structure of idiosyncratic income shock and with limited risk sharing among individuals, they lead to a tight link between income and consumption inequality. The rising economic inequality could be the growing pain associated with the economic transition.

\section{APPENDIX}

\section{A Variable Definition}

1. Household $(\mathrm{HH})$ earnings: regular earnings, temporary earnings and bonuses of $\mathrm{HH}$ head, spouse, and other HH members.

2. Gross income: HH earnings + private transfers + asset income.

3. Pretax income: gross income + public pension benefits + other social security benefits.

4. Disposable income: pretax income - taxes.

5. Consumption: food, clothing, household appliances, health, transportation and communications, education and entertainment, housing rent and utilities, and other. $^{25}$

6. Durable consumption: durable goods for household appliances, transportation tools, communication tools, durable goods for entertainment.

7. Nondurable consumption $=$ consumption - durable consumption - housing rent.

\footnotetext{
${ }^{25}$ For housing rent, if it is an owner-occupied house, we take the "imputed" rent variable from the UHS. If the house is rented, we take the actual rent.
} 


\section{B Panel Construction from the UHS}

The trackable household IDs are the basis for constructing short panels from the UHS data. We merge the UHS every two years and keep the household IDs which show up in both years in the combined data. We then check the household head's age in the combined data to see if it increases when the year increases. For example, we merge the 1986 and 1987 UHS into a combined dataset. We only keep those households whose IDs appear in both 1986 and 1987. We then check that, for example, if a household head's age is 25 in 1986, his age has increased to 26 in 1987. We drop observations that do not satisfy this criterion. After the age check, we also go to the remaining sample to visually check each observation to see if its variables make sense (for example, that the gender does not change over the sample).

For the UHS data before 2007, we have a three-year rotation structure. Therefore we could further merge those two-year combined data into a three-year short panel that we use for the "difference" method in estimating income dynamics. For example, we merge 1986-87 data with 1987-88 data to form a 1986-1988 three-year panel. Again, we only keep those households in the data whose IDs show up in both periods. And we check ages of the heads of households to make sure they are consistent. For the UHS data after 2007, we only have a two-year rotation panel structure. Therefore we do not further merge data into the three-year panel.

The second column in Table 3 shows the sample size of the three-year panel constructed through the procedure above that we use for the "difference" method. ${ }^{26}$ The second column in Table 4 shows the sample size of the two-year panel constructed for the estimation using the "level" method.

To make sure that the panel data sample we constructed is nationally representative and also consistent with the original data, we report the sample means of key characteristic variables of the constructed three-year panel and sample A in Table $5 .^{27}$ As we can see, the sample means of variables are broadly consistent with the sample

\footnotetext{
${ }^{26}$ The household ID is misidentified in 1991; therefore we cannot construct the three-year panel for 1989-1991, 1990-1992 and 1991-1993. There is a change in household ID definition after 2001; therefore we cannot match household ID in a three-year panel for periods 2000-2002 and 2001-2003. The sample size of constructed three-year panel is strictly limited before 1991. For example, the periods 1986-88 and 1987-89 only have 33 observations in each panel; therefore, for the analysis, we restrict our three-year panel only to the time period from 1992 to 2007.

${ }^{27}$ UHS categorizes education attainment on a scale $1-9$, where 1 is no schooling, 3 is finishing elementary school, 5 is finishing high school, 8 is college graduate, and 9 is postgraduate.
} 
Table 3: Panel Construction from UHS: Three-year Panel for Difference Method

\begin{tabular}{|l|l|l|}
\hline Year & \# of HHs & \# of HHs (relaxed age restriction) \\
\hline $1992-94$ & 140 & 387 \\
$1993-95$ & 263 & 526 \\
$1994-96$ & 162 & 1176 \\
$1995-97$ & 152 & 437 \\
$1996-98$ & 137 & 346 \\
$1997-99$ & 506 & 841 \\
$1998-2000$ & 293 & 515 \\
$1999-2001$ & 401 & 657 \\
$2002-2004$ & 8636 & 8975 \\
$2003-2005$ & 3780 & 4030 \\
$2004-2006$ & 4120 & 4374 \\
$2005-2007$ & 1187 & 2355 \\
\hline
\end{tabular}

Source: UHS 1986-2009.

means of the original UHS data.

To mitigate possible measurement error caused by our age restriction in constructing panels and also increase the sample size of the constructed panels, we also relax the age restriction by allowing ages for the next year fall into a \pm 1 range. For example, for a household head aged 25 in 1986, we now allow his age to be either 25 or 27 in 1987 for the relaxed age restriction panels. As shown in the third column in tables 3 and 4 , the sample size of each short panel significantly increases.

Using the panels with the relaxed age restriction, we rerun the estimation for both "difference" and "level" method. We report the estimates of $\sigma_{\eta, t}$ and $\sigma_{\varepsilon, t}$ in Figure 24. As one can see, the results are largely similar to the ones in Figure 20.

\section{Methodology of Income Dynamics Estimation}

We estimate the variances of the permanent and transitory income shocks $\left(\sigma_{\eta, t}\right.$ and $\left.\sigma_{\varepsilon, t}\right)$ using either the "difference" or "level" method.

For the "difference" method, we need at least a three-year panel. We first define a 
Table 4: Panel Construction from UHS: Two-year Panel for Level Method

\begin{tabular}{|l|l|l|}
\hline Year & \# of HHs & \# of HHs (relaxed age restriction) \\
\hline $1992-93$ & 1109 & 1631 \\
$1993-94$ & 684 & 1174 \\
$1994-95$ & 1289 & 1912 \\
$1995-96$ & 1648 & 2418 \\
$1996-97$ & 475 & 891 \\
$1997-98$ & 1118 & 1478 \\
$1998-99$ & 1731 & 2218 \\
$1999-00$ & 791 & 1095 \\
$2000-01$ & 2098 & 2434 \\
$2002-03$ & 12133 & 12397 \\
$2003-04$ & 15939 & 16150 \\
$2004-05$ & 7629 & 7940 \\
$2005-06$ & 17011 & 17252 \\
$2006-07$ & 1382 & 2736 \\
\hline
\end{tabular}

Source: UHS 1986-2009.

Table 5: Sample Mean of Constructed Three-Year Panel and Original UHS: Comparison

\begin{tabular}{|l|l|l|l|l|l|l|l|l|l|l|l|l|}
\hline Year $\backslash$ Var & \multicolumn{2}{l|}{ Age } & \multicolumn{2}{l|}{ \% Male } & \multicolumn{2}{l|}{ \% Married } & \multicolumn{2}{l|}{ Education } & \multicolumn{2}{l|}{ \% SOE worker } & \multicolumn{2}{l|}{ HH Size } \\
\cline { 2 - 6 } & Panel & UHS & Panel & UHS & Panel & UHS & Panel & UHS & Panel & UHS & Panel & UHS \\
\hline $1993-95$ & 46.6 & 45.6 & 67.7 & 68.0 & & & 3.7 & 3.9 & 73.5 & 66.1 & 3.2 & 3.2 \\
$1994-96$ & 46.7 & 45.8 & 67.2 & 66.6 & & & 3.9 & 3.9 & 61.3 & 65.8 & 3.2 & 3.2 \\
$1995-97$ & 45.3 & 46.0 & 69.3 & 66.2 & & & 3.9 & 3.9 & 68.3 & 65.8 & 3.1 & 3.2 \\
$1996-98$ & 43.8 & 46.3 & 64.1 & 65.1 & & & 3.9 & 3.9 & 74.3 & 64.7 & 3.1 & 3.2 \\
$1997-99$ & 45.5 & 46.5 & 62.0 & 64.1 & & & 3.9 & 3.8 & 63.5 & 63.1 & 3.1 & 3.1 \\
$1998-00$ & 46.9 & 47.0 & 62.6 & 64.6 & & & 3.9 & 3.8 & 64.0 & 60.0 & 3.2 & 3.1 \\
$1999-01$ & 47.7 & 47.4 & 69.0 & 66.3 & & & 3.8 & 3.8 & 59.1 & 57.4 & 3.1 & 3.1 \\
$2002-04$ & 48.2 & 48.5 & 70.9 & 70.5 & 95.1 & 94.2 & 5.4 & 5.3 & 54.1 & 50.1 & 3.0 & 2.9 \\
$2003-05$ & 48.4 & 48.7 & 67.6 & 70.7 & 94.9 & 93.8 & 5.4 & 5.4 & 52.3 & 47.1 & 3.0 & 2.9 \\
$2004-06$ & 49.5 & 49.0 & 63.3 & 70.5 & 94.0 & 93.6 & 5.4 & 5.4 & 47.3 & 45.2 & 2.9 & 2.9 \\
$2005-07$ & 47.1 & 49.1 & 74.4 & 70.2 & 94.6 & 93.5 & 5.5 & 5.5 & 43.5 & 43.6 & 3.0 & 2.9 \\
\hline
\end{tabular}

Source: UHS 1986-2009. 
Figure 24: Transitory versus Permanent Income Shocks: Relaxed Age Restriction
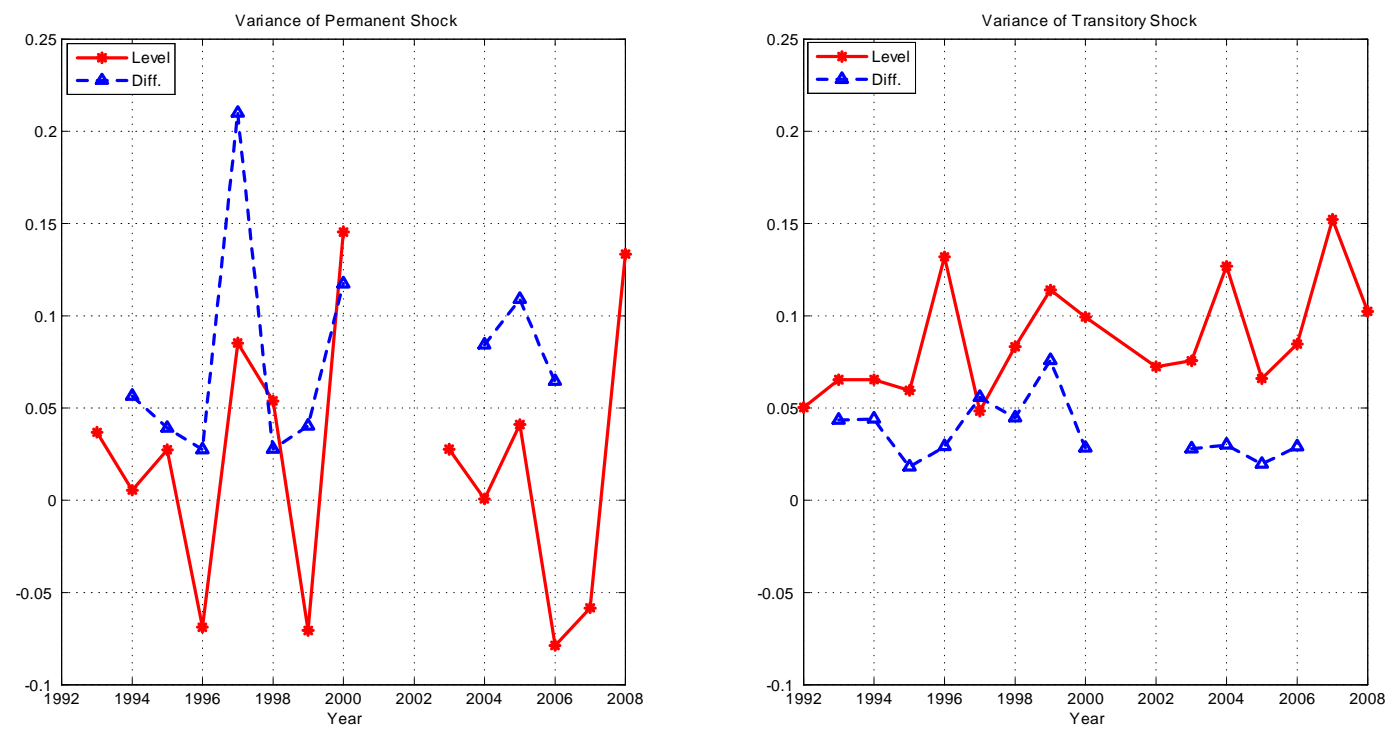

first-difference

$$
\triangle w_{i, c, t} \equiv w_{i, c, t}-w_{i, c, t-1}=\eta_{i, c, t}+\varepsilon_{i, c, t}-\varepsilon_{i, c, t-1}
$$

Following this expression, we have

$$
\begin{aligned}
\operatorname{cov}_{c}\left(\Delta w_{i, c, t+1}, \Delta w_{i, c, t}\right) & =-\sigma_{\varepsilon, c, t} \\
\operatorname{var}_{c}\left(\Delta w_{i, c, t}\right) & =\sigma_{\eta, c, t}+\sigma_{\varepsilon, c, t}+\sigma_{\varepsilon, c, t-1}
\end{aligned}
$$

We then identify $\sigma_{\varepsilon, c, t} \forall t$ from equation (3) for different years. Knowing $\sigma_{\varepsilon, c, t}$ for all $t$, we can then identify $\sigma_{\eta, c, t}$ from equation (4). Finally, we average out $\sigma_{\varepsilon, c, t}$ and $\sigma_{\eta, c, t}$ across all cohorts $c$ at year $t$ to obtain $\sigma_{\varepsilon, t}$ and $\sigma_{\eta, t}$.

For the "level" method, we need at least a two-year panel. We first form the level moment

$$
w_{i, c, t+1}=z_{i, c, t}+\eta_{i, c, t+1}+\varepsilon_{i, c, t+1}
$$

Based on this expression, we have

$$
\begin{aligned}
& \operatorname{var}_{c}\left(w_{i, c, t}\right)-\operatorname{cov}_{c}\left(w_{i, c, t+1}, w_{i, c, t}\right)=\sigma_{\varepsilon, c, t} \\
& \operatorname{var}_{c}\left(w_{i, c, t}\right)-\operatorname{cov}_{c}\left(w_{i, c, t}, w_{i, c, t-1}\right)=\sigma_{\eta, c, t}+\sigma_{\varepsilon, c, t}
\end{aligned}
$$


We then identify $\sigma_{\varepsilon, c, t}$ from (5). And based on that identification, we can further identify $\sigma_{\eta, c, t}$ from (6). Finally, we average out $\sigma_{\varepsilon, c, t}$ and $\sigma_{\eta, c, t}$ across all cohorts $c$ at year $t$.

\section{References}

[1] Appleton, Simon, John Knight, Lina Song, and Qingjie Xia (2002), "Labor Retrenchment in China: Determinants and Consequences," China Economic Review, 13, 252-275.

[2] Blundell, R., L. Pistaferri, and I. Preston (2008), "Consumption Inequality and Partial Insurance," American Economic Review, 98(5), 1887-1921.

[3] Cai H., Y. Chen, L-A Zhou (2010), "Income and Consumption Inequality in Urban China: 1992-2003," Economic Development and Cultural Change, 58, $385-413$.

[4] Campell J., and N. Mankiw (1989), "Consumption, Income and Interest Rates: Reinterpreting the Time Series Evidence," In NBER Macroeconomics Annual 1989, volume 4, 185-246. Cambridge, Massachusetts: National Bureau of Economic Research.

[5] Castaneda, A., J. Diaz-Gimenez, and V. Rios-Rull (2003), "Accounting for the U.S. Earnings and Wealth Inequality," Journal of Political Economy, 114(4), $818-857$.

[6] Chamon, M. D., and E. Prasad (2010), "Why are Saving Rates of Urban Households in China Rising?" American Economic Journal: Macroeconomics, 93-130.

[7] Deaton, A., and C. Paxson (1994), "Intertemporal Choice and Inequality," Journal of Political Economy, 102(3), 437-467.

[8] Feng, S., Y. Hu and R. Moffitt (2015), "Long Run Trends in Unemployment and Labor Force Participation in China," NBER Working Paper No. 21460.

[9] Ge, S., and D. T. Yang (2014), "Changes in China's Wage Structure," Journal of the European Economic Association, 2014, 12(2), 300-336. 
[10] Gorodnichenko, Y., K.S. Peter, and D. Stolyarov (2010), "Inequality and Volatility Moderation in Russia: Evidence from Micro-level Panel Data on Consumption and Income," Review of Economic Dynamics, 13, 209-237.

[11] He, H., F. Huang, Z. Liu and D. Zhu (2015), "Breaking 'Iron Rice Bowl' and Precautionary Saving: Evidence from Chinese State-Owned Enterprises Reform," Working Paper, Shanghai University of Finance and Economics.

[12] He, H., L. Ning, and D. Zhu (2015), "Rapid Aging and Pension Reform: The Case of China," Working Paper, Shanghai University of Finance and Economics.

[13] Heathcote, J., F. Perri, and G. Violante (2010), "Unequal We Stand: An Empirical Analysis of Economic Inequality in the United States, 1967-2006," Review of Economic Dynamics, 13, 15-51.

[14] Hsieh, C,-T., and Z. Song (2015), "Grasp the Large, Let Go of the Small: The Transformation of the State Sector in China," NBER Working Paper No. 21006.

[15] Kaplan, G., G. Violante and J. Weidner (2014): "The Wealthy Hand-to-Mouth," Brookings Papers on Economic Activity (Spring 2014), 77-138.

[16] Krueger D., and F. Perri (2006), "Does Income Inequality Lead to Consumption Inequality? Evidence and Theory," Review of Economic Studies, 73, 163-193.

[17] Krueger, D., F. Perri, L. Pistaferri, and G. Violante (2010), "Cross-sectional Facts for Macroeconomists," Review of Economic Dynamics, 13, 1-14.

[18] Lise, J., N. Sudo, M. Suzuki, K. Yamada, and T. Yamada (2014), "Wage, Income and Consumption Inequality in Japan, 1981-2008: From Boom to Lost Decades," Review of Economic Dynamics, 17, 582-612.

[19] Santaeulalia-Llopis, R. and Y. Zheng (2015), "The Price of Growth: Consumption Insurance in China 1989-2009," Working Paper, City University of Hong Kong.

[20] Song, Z., and D.T. Yang (2010), "Life Cycle Earnings and Saving in a FastGrowing Economy," mimeo, Chinese University of Hong Kong.

[21] Wei, Shang-Jin, and Xiaobo Zhang (2011), "The Competitive Saving Motive: Evidence from Rising Sex Ratios and Savings Rates in China," Journal of Political Economy, 119, 511-564. 